\title{
DIFFERENTIATION OF THE BULBAR MOTOR NUCLEI AND THE COINCIDENT DEVELOP- MENT OF ASSOCIATED ROOT FIBERS IN THE RABBIT
}

\author{
DONALD L. KIMMEL \\ Department of Anatomy, University of Michigan, ${ }^{1}$ Ann Arbor \\ THIRTY-ONE FIGURES
}

CONTENTS

Introduction

Material and methods $\ldots \ldots \ldots \ldots \ldots \ldots \ldots \ldots \ldots \ldots \ldots \ldots \ldots \ldots$

General survey of the literature $\ldots \ldots \ldots \ldots \ldots \ldots \ldots \ldots \ldots \ldots \ldots \ldots$

Deseription of material studied $\ldots \ldots \ldots \ldots \ldots \ldots \ldots \ldots \ldots \ldots \ldots \ldots$

Somatic efferent component. Its central and peripheral development ... 86

The hypoglossal $\ldots \ldots \ldots \ldots \ldots \ldots \ldots \ldots \ldots \ldots \ldots \ldots \ldots \ldots \ldots$

The abducens $\ldots \ldots \ldots \ldots \ldots \ldots \ldots \ldots \ldots \ldots \ldots \ldots \ldots \ldots$

Visceral efferent component. Its central and peripheral development . . . 103

The vago-accessory $\ldots \ldots \ldots \ldots \ldots \ldots \ldots \ldots \ldots \ldots \ldots \ldots \ldots$

The glossopharyngeal $\ldots \ldots \ldots \ldots \ldots \ldots \ldots \ldots \ldots \ldots \ldots \ldots \ldots \ldots$

The facial $\ldots \ldots \ldots \ldots \ldots \ldots \ldots \ldots \ldots \ldots \ldots \ldots \ldots \ldots \ldots \ldots$

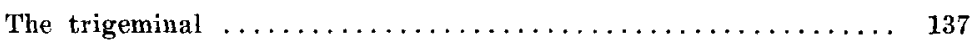

General discussion $\ldots \ldots \ldots \ldots \ldots \ldots \ldots \ldots \ldots \ldots \ldots \ldots \ldots \ldots \ldots \ldots$

\section{INTRODUCTION}

This present study concerns itself primarily with the ontogenetic development of the nuclear centers of bulbar cranial nerves in the rabbit and with the embryonic and adult distributions of their branches. Its purpose is to show that the central development proceeds stage for stage with the pro-

A dissertation submitted in partial fulfilment of the requirements for the degree of doctor of philosophy in the University of Michigan. 
gressive peripheral differentiation, and that the one is a reflection of the other.

It is a pleasure at this time to express my appreciation of the numerous privileges granted me by the Department of Anatomy of the University of Michigan, among which was the opportunity of studying the microscopic preparations of rabbit material from the Huber Neurological Collection. I especially wish to extend my most sincere thanks to Dr. Elizabeth C. Crosby for her kindly criticism, encouragement, and untiring efforts in my behalf.

\section{MATERIAL AND METHODS}

Series of embryo brains (in many instances whole heads) and of young and adult brains of the rabbit (Lepus cuniculus) from the Huber Neurological Collection were used for this study. Thirty-five of the young and embryo brains had been prepared by the modified pyridine silver technique (Huber and Guild, '13) and sectioned in various planes, and an adult brain had been cross sectioned and stained by the toluidin blue method.

The ontogenetic development of the nuclear centers and the associated differentiation of their peripheral branches were studied by the usual microscopic methods, the sections of the embryonic material being outlined to scale for all levels and each stage and the peripheral branches and the nuclei plotted in position. In this way the exact course and specific relations of each branch were obtained and used as a basis for the description. From the adult material graphic reconstructions of the cranial nerve nuclei (see figs. 18-20) were made by means of camera lucida drawings and plotted to scale $(\times 40)$. Since, for future experimental work, an exact three-dimensional picture of these nuclei in position was considered valuable, a wooden base was built, in accordance with measurements obtained from one of the series, to represent the hollowed-out brain stem and then several of the cranial nerve nuclei were 
reconstructed in blotting paper to the same scale $(X 20)$ and mounted in position.

\section{GENERAL SURVEY OF THE LITERATURE}

Numerous excellent contributions have already been presented by various investigators on the ontogenetic and phylogenetic development and the adult structure of mammalian cranial nerve nuclei and the peripheral distribution of the cranial nerves. The specific results of these studies will be considered in connection with the detailed description of the present material but certain of them should receive special mention here. Among such are the studies of Streeter ('05, '08, '12) in the field of human embryology and of Ariëns Kappers ('12) on the development of various cranial nerve nuclei in phylogeny, as well as his work ('10, '11, '13 and elsewhere), and that of Black ('17), on neurobiotaxis. The manner of differentiation of the various nuclear columns of the brain stem is better understood from a consideration of the work of Mesdag ('09), Bok ('15), Tello ('22), and Windle ('33). Contributions on the visceral afferent component have been presented by Hunt ('08), Allen ('23), Dubois ('29), Barnard ('36), and many others. The morphology of the trigeminal nerve complex has been a matter of interest to numerous observers, among whom are Dixon (1896), Wallenberg (1897), Bochenek ('01), Johnston ('09), Allen ('19), Castaldi ('23), Weinberg ('28), Sheinin ('32), and Woodburne ('36). The reconstructions by Weed ('14) of the nuclear masses of the human brain stem and those of Kooy ('17) of the inferior olive of vertebrates, the observations of Stuurman ('16, '16 a) on the hypoglossal gray, the work of Kosaka and Yagita ('05) on the origin of the vagus nerve and its central endings, the studies of Papez ('27) on the subdivisions of the facial nucleus, Addens' ('33) paper dealing with the possibility of crossing root fibers of the facial, acoustic, glossopharyngeal and vagus nerves, and the work of Ariëns Kappers ('14) on the gustatory components of the facial, glossopharyngeal, and vagus nerves have also been consulted freely in preparing the pres- 
ent paper. Among the reference texts used in this study are those by Dejerine (1895), van Gehuchten (1897), Sabin ('01), Ramón y Cajal ('09-'11; see also 1895), Arey ('31), and particularly Winkler and Potter ('11), Keibel and Mall ('12), and Ariëns Kappers, Huber and Crosby ('36).

\section{DESCRIPTION OF MATERIAL STUDIED}

Somatic Efferent Component. Its Central and Peripheral Development

The hypoglossal

In the 11-day embryo. All of the efferent cranial nerves, at this age, have their origin in a common cell column extending throughout the brain stem. This column, previously described by Mesdag ('09), Bok ('15), and Tello ('22) for birds, and by Windle ('33) for mammals, is located in the basal plate of the mantle layer. Caudally it is continuous with a similarly located (but slightly more differentiated) cell column in the spinal cord (fig. 1a). Rostrally it is less well developed and, slightly in front of the level of the emergent oculomotor root, processes from the less differentiated neurons of this layer are no longer evident in silver preparations. The cells of this column are bipolar, with a larger, better developed process extending toward the periphery and a shorter one (merely an apical tip of the cell body) usually directed medialward. They possess a fairly distinct nucleus and a small amount of neurofibrillar material near their surface, particularly in that part of the cell body giving origin to a process.

The hypoglossal portion of this cell column lies in the caudalmost neuromere 2 of the medulla oblongata (fig. 1a), and its most rostral and most caudal cells can be determined only by tracing their neuraxes, since there is no differentiation of any type in the cell column. Such neuraxes pass slightly lateralward and ventralward from the cell body and, as they lie among the arcuate fibers, combine into numerous small fascicles which emerge from the ventral surface of the brain stem. The emergent fascicles converge to form a stronger caudal and a weaker cephalic root. These two roots, which course caudally and slightly ventrally along the dorsal wall of the anterior cardinal vein, unite into a common trunk opposite the level of emergence of the third cervical nerve from the eord. At this place of union these roots are joined by branches from the first and second cervical nerves (fig. 2), and then the combined trunk extends caudally along

'Sixth rhombic groove or neuromere of Streeter ('12, in Keibel and Mall, vol. 2, fig. 95, p. 135). 


\section{ABBREVIATIONS}

a, area in figure 1 illustrated in detail in figure $1 \mathrm{a}$

A, rostral neuromere giving origin to trigeminal nerve

abd.n., abducens nucleus

abd.N., abducens nerve

aber.br. of VIN., aberrant branch of abducens nerve

acc.n.VI, accessory nucleus of abducens

a-f.gang., acoustico-facial ganglionic complex

amb.n., nucleus ambiguus

ant.div.mand.r., anterior division of mandibular ramus of the trigeminal nerve

aorta, dorsal aorta

asc.br.VII, branches of VII ascending toward genu

$b$, area in figure 1 illustrated in detail in figure $1 \mathrm{~b}$

$B$, caudal neuromere giving rise to trigeminal nerve

b.a.1, first branchial areh

b.a.2, second branchial arch

b.a.3, third branchial areh

br. to tr. and s., branch to the trapezius and sternocleidomastoid muscles

buc.br.V, buceinator branch of the trigeminal

$C$, the neuromere associated with the abducens

c1, first cervical nerve

c2, second cervical nerve

c7, seventh cervical nerve

c.c., central canal

c.mig.cells VII, caudal group of migrating cells of the facial nucleus

c.p.mot.n.V, caudal part of the motor trigeminal nucleus

c.t., chorda tympani

cer., cerebellum

ch.sens.n.V, chief sensory nucleus of the trigeminal

cil.br., ciliary branches

coel.plx., coeliac plexus

com.ef.col., common efferent column com.v.ef.col., common visceral efferent cell column

d, area in figure 5 illustrated in detail in figure $5 \mathrm{~d}$

D, neuromere associated with the central origin of the facial nerve

dif.gen.gang., differentiating geniculate ganglion

dor.ef.n., dorsal efferent nucleus

dor.rt.gang., dorsal root ganglion

dor.sec.asc.tr. of $\mathrm{V}$, dorsal secondary ascending tract of $\mathrm{V}$

$E$, neuromere associated with the central origin of the glossopharyngeal nerve

Ed.West.n., Edinger-Westphal nucleus epend.l., ependymal layer

ex.arc.f., external arcuate fibers

F, neuromere associated with the central origin of the vagus and hypoglossal nerves

F.gang., Froriep's ganglion

fac.n., facial nucleus

fac.N., facial nerve

fase.sol. $+\mathrm{n}$, fasciculus solitarius and nucleus

fr.N., frontal nerve

g.s.p.N., greater superficial petrosal

nerve

gang.er., ganglionic crest

gen.vise.ef.col., general visceral efferent column

genu VIr, genu of the facial nerve

glossoph.N., glossopharyngeal nerve

hip., hippocampus

hyp.n., hypoglossal nucleus

hyp.N., hypoglossal nerve

ind.mot.rt.V, indirect motor root of the trigeminal

inf.alv.N., inferior alveolar nerve

inf.col, inferior collieulus

inf.l.N., inferior laryngeal nerve

inf.o.N., infraorbital nerve

inf.sal.n., inferior salivatory nucleus

int.arc.f., internal arcuate fibers

int.car.a., internal carotid artery 
int.jug.v., internal jugular vein j.gang., jugular ganglion

lab.br., labial branch

lat.ret.n., lateral reticular nucleus

ling.br.V, lingual branch of the trigeminal

ling.br.IX, lingual branch of the glossopharyngeal

ling.N., lingual nerve

m.h.br., mylohyoid branch

m.l., medial lemniscus

m.l.f., medial longitudinal fasciculus

mand.p., mandibular process

mand.r., mandibular ramus

mass.br., masseteric branch of the trigeminal

max.p., maxillary process

max.r., maxillary ramus

med.r.n., medial reticular nucleus

men.br., mental branch of the inferior alveolar nerve

mes., mesencephalon

mig.cells of $\mathrm{V}$, migrating cells of the trigeminal motor nucleus

mig.s.v.ef.eells of VII, migrating special visceral efferent cells of the facial nucleus

mot.n.V, motor nucleus of the trigemi nal nerve

mot.n.VII, motor nucleus of the facial nerve

mot.rt.V, motor root of the trigeminal mot.rt. of $\mathrm{V}+\mathrm{n}$., motor root of the trigeminal nerve and nucleus

n.br., nasal branch

n.gang., nodose ganglion

n.inter., nucleus intercalatus

n. of fasc.sol., nueleus of the fasciculus solitarius

n. of m.rt. of V, nucleus of the mesencephalic root of the trigeminal

n. of m.rt. of $\mathrm{V}+1 . \mathrm{c}$, nucleus of the mesencephalic root of the trigeminal and locus coeruleus

n. of Rol., nucleus of Roller

n. (of) sp.rt. of V, nucleus of spinal root of the trigeminal

N.int., nervus intermedius neopal., neopallium

o.c., optic eup

o.r., ophthalmic ramus

ocul.n., oculomotor nueleus

ocul.N., oculomotor nerve

oesop.plx., oesophageal plexus

opt.N., optic nerve

ot.v., otic vesicle

p.semic., semicircular portion of developing ear

p.vest.n., primordial vestibular nucleus pal.br., palatine branch

periv.g., perventricular gray

pet.gang., petrosal ganglion

phar.br.IX, pharyngeal branch of the glossopharyngeal nerve

phar.br.X, pharyngeal branch of the vagus nerve

post.div.mand.r., posterior division of the mandibular ramus of the trigeminal nerve

pul.plx., pulmonary plexus

pyr., pyramid

$r$, synapse of fibers from the nucleus of the mesencephalic root of the trigeminal nerve about motor facial cells

r.mig.cells VII, rostral group of migrating cells of the facial nueleus

rt. of N.int., root of nervus intermedius

$s$, synapse of fibers originating in the geniculate about motor facial cells

s.o., superior olive

sec.asc.tr. of V, secondary ascending tract of trigeminal

semil.gang., semilunar ganglion

sens.area, sensory area

sens.rt.V, sensory root of the trigeminal sens.rt. $V$ to cer., sensory root of the trigeminal to the cerebellum

sens.rt.IX, sensory root of the glossopharyngeal

som.ef.eol, somatic efferent column

sp.ace.n., spinal accessory nucleus

sp.acc.N., spinal accessory nerve

sp.acc.rt., spinal accessory root

sp.c., spinal cord

sp.rt. of $\mathrm{V}$, spinal root of the trigemi.

nal nerve 
sp.rt. of $\mathrm{V}+\mathbf{n}$, spinal root of the trigeminal nerve and nucleus

sp.visc.ef.cells, special visceral efferent cells

sp.visc.ef.col., special visceral efferent column

sph.pal.br., sphenopalatine branch of the maxillary ramus of the trigeminal nerve

stom., stomach

sup.alv,n, superior alveolar nueleus

sup.alv.N., superior alveolar nerve

sup.col., superior colliculus

sup.gang., superior ganglion of the glossopharyngeal nerve

sup.l.N., superior laryngeal nerve

sup.sal.n., superior salivatory nucleus sym.tr., sympathetic trunk

t.br., tympanie branch

t.sp.t., tectospinal tract

tel., telencephalon

trig.N., trigeminal nerve troch.n., trochlear nucleus

troch.N., trochlear nerve

$\mathrm{v}$, vestibular fibers to medial longitudinal faseiculus

v.c.n., ventral cochlear nucleus

v.fac.n., ventral facial nucleus

v.fun., ventral funiculus of spinal cord v.sec.asc.tr. of $V$, ventral secondary asconding tract of the trigeminal nerve v.sp.cer.tr., ventral spino-cerebellar tract vagus $N$., vagus nerve

vagus rts., vagus roots

vest.N., vestibular nerve

$w$, small cells of superior salivatory nucleus

$x$, large cells of superior salivatory nucleus

$y$, small cells of dorsal efferent nucleus $\mathrm{z}$, large cells of dorsal efferent nucleus IVv, fourth ventricle VIII N., eighth nerve

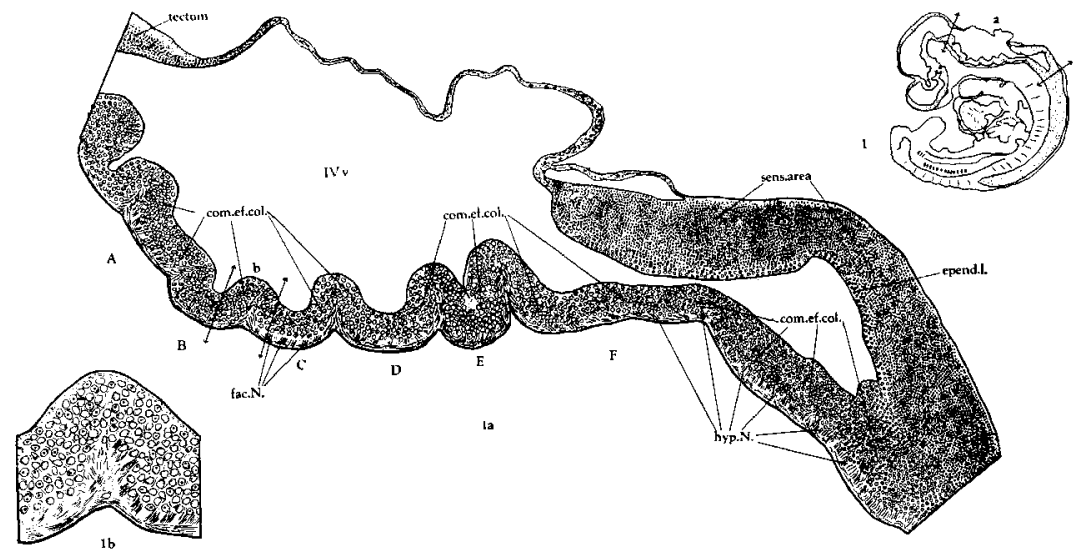

Fig. 1 Drawing of a sagittal section of an 11-day rabbit embryo, stained with pyridine silver to indicate general relations and to serve as a key drawing for figure 1a. $\times 4$.

Fig. 1a Enlargement of area indicated at ' $a$ ' on figure 1. This section shows especially the neuromeres (A to $F$ ) and the common efferent column. Note the rootlets of the hypoglossal nerve. $\times 50$.

Fig. 1b Enlargement of adjoining portions of neuromeres $B$ and $C$ to show the neurons of the region. $\times 150$. 


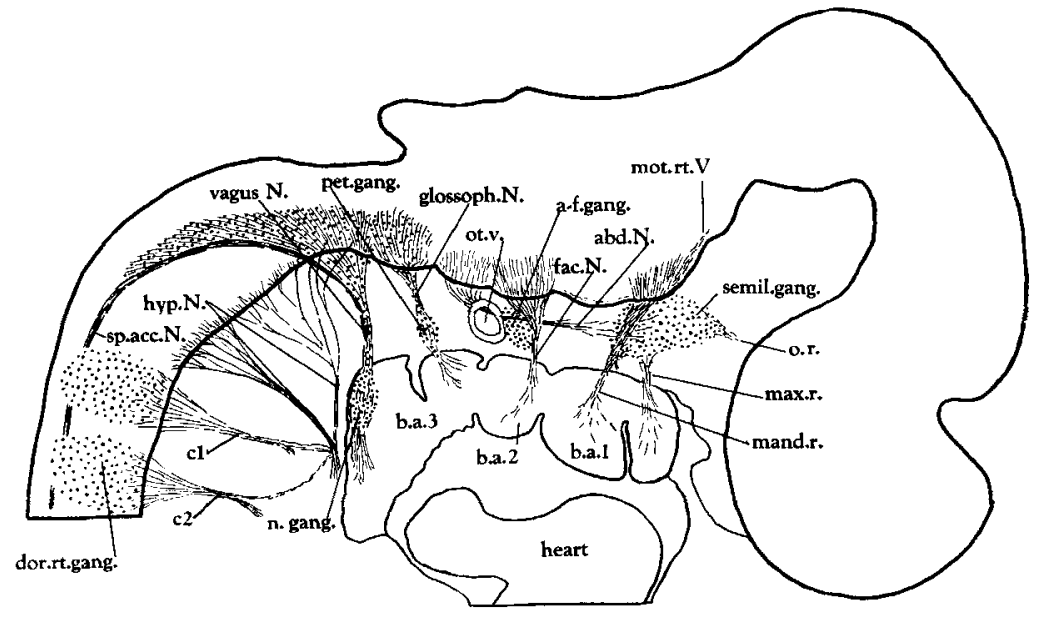

Fig. 2 A graphic reconstruction in the sagittal plane of an 11-day rabbit embryo, showing the brain and upper cord, the associated nerres, and stressing particularly the peripheral distribution of the branehing of such eranial and spinal nerves. Based on a sagittal series prepared by pyridine silver technique. $\times 40$.

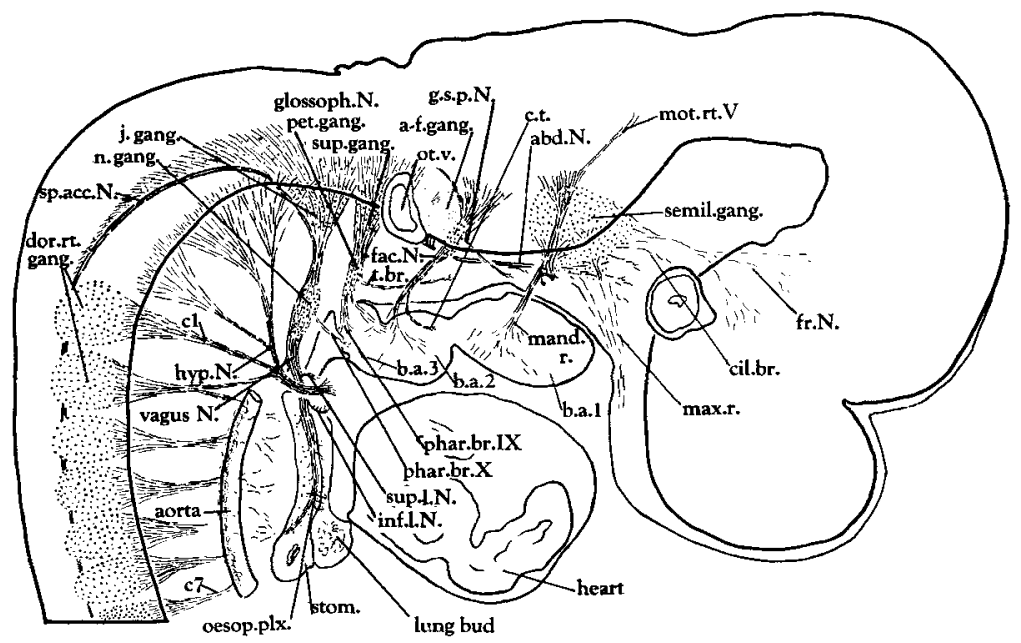

Fig. 3 A similarly prepared graphic reconstruction in the sagittal plane of a 12-day rabbit embryo. The material is stained in pyridine silver and shows the brain and upper spinal eord and illustrates partieularly the distribution of the peripheral fibers of the cranial nerves. $\times 30$. 
the dorsolateral wall of the anterior cardinal vein for a short distance to terminate within the mesenchyme by dividing into numerous, fine, slightly knobbed endings.

In the 12-day embryo. The hypoglossal cells have become lemonshaped rather than spherical, as earlier, and have increased in number and in bipolarity. Although not segregated from the common column of origin of the efferent bulbar nerves, those cells giving rise to the hypoglossal nerve are concentrated in the area ventrolateral to the fourth ventricle, in the medial and particularly in the caudomedial portion of this common bulbar cell column. The most rostral and most caudal cells contributing to this nerve can again be determined only by tracing the neuraxes centrally.

In accordance with the greater number of cells contributing to the nerve there are more and stronger fasciculi coursing ventrolaterally through the arcuate fibers to emerge from the ventral surface of the medulla oblongata. These emerging fasciculi, as in the 11-day embryo, have combined into two roots, of which, at this age, the cephalic is the stronger (fig. 3 ). As these two roots course caudad in the mesenchyme, they combine into a single bundle. which has essentially the same relations as does the comparable trunk of the 11-day stage but which extends somewhat farther caudad and courses lateral to the anterior cardinal vein as the root turns ventrally to approach the region of the tongue anlagen. Its fibers terminate at the level of the laryngeal groove.

In the 13-day, 2-hour embryo. By this stage, the cells of origin of the hypoglossal nerve are gathered into a definite somatic efferent nuclear column located elose to the ventrolateral wall of the ventricle and ventromedial to the now differentiated visceral efferent cell column (fig. 8). Along the rostral two-thirds of the nuclear column, about its dorsal, medial, and lateral aspects, there are small-celled nuclear masses (fig. 8) which will be discussed later (see p, 95). The highest fibers of the first cervical nerve and the lowest fibers of the hypoglossal nerve again must be traced centrally to allocate to each its appropriate central gray, but the cephalic limit of the hypoglossal cell column can be determined by the narrowing of the gray and by a final disappearance of hypoglossal constituent neurons at a level just caudal to the emergent glossopharyngeal nerve.

As the fasciculi of the hypoglossal nerve are followed toward the periphery of the medulla oblongata and then caudad through the mesenchyme, they converge into the usual two roots (fig. 4). However, these roots now lie dorsomedial instead of dorsal to the anterior cardinal vein and, farther caudad, as they join to form a single trunk, are quite proximate to the dorsal wall of the nodose ganglion (fig. 4). 
This new relation to the anterior cardinal venous system can be explained by changes of the developing venous system of this area rather than by a shifting of the nerve medially (Keibel and Mall, '12, vol. 2, p. 677). At the inferior border of the nodose ganglion the hypoglossal nerve is joined by the branches from the first and second cervical nerves (fig. 4). Then the combined trunk swings ventrolaterally between the vagal trunk and the anterior cardinal vein and, after passing lateral to the second aortic arch at the level of the tracheal groove,

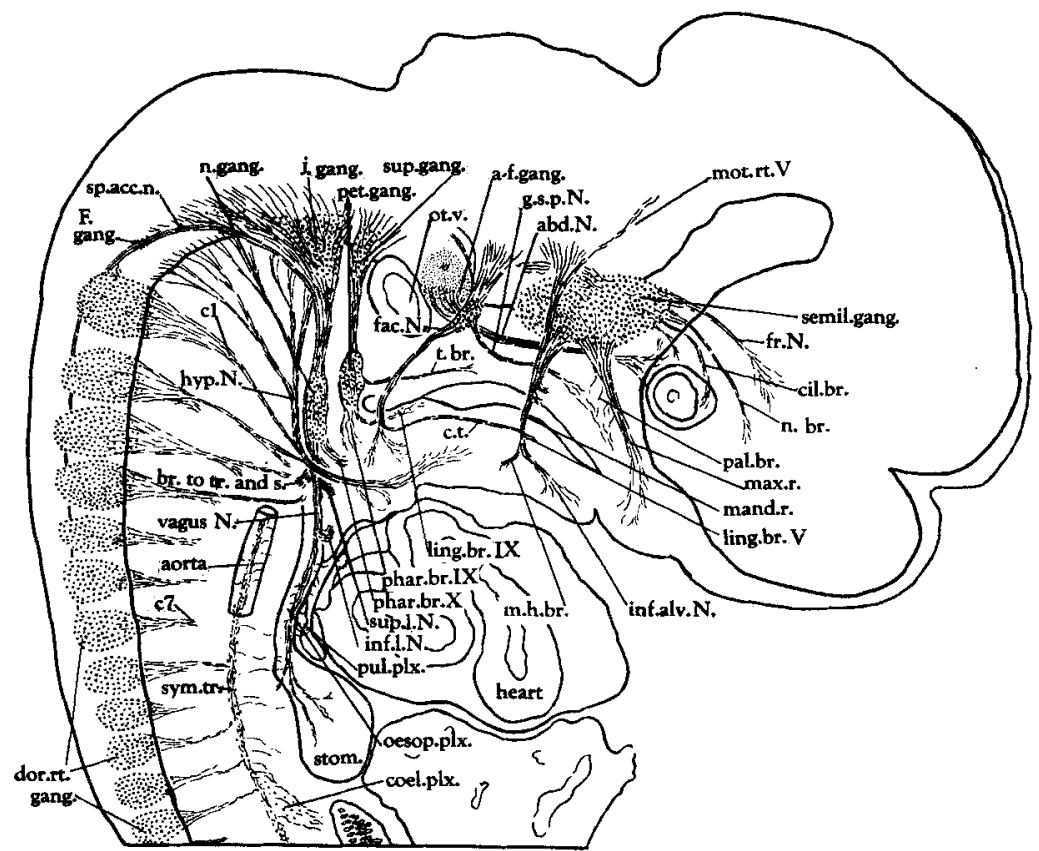

Fig. 4 A graphic reconstruction of the brain and upper spinal cord regions of a 13-day, 2-hour rabbit embryo showing the peripheral course and distribution of many of the cranial nerves. This figure should be compared with figures 2 and 3 . $\times 19.5$.

curves rostromedially to enter the developing lower jaw, where it terminates just dorsal to the primitive tongue bud.

In the 14-day, 6-hour embryo. Due to a greater contrast between the darker staining neurons and the light staining neurogliar cells, the hypoglossal nucleus is more highly emphasized in this than in the previous stage. A few of its neurons are now multipolar. Caudally the column is still continuous with the cervical cord gray. 
Peripherally the relations of the hypoglossal branches are much the same as in the previous stage. However, a fine fascicle from the third cervical nerve now combines with the bundles of the first and second cervical nerves which are distributed with the hypoglossal and hypoglossal branches extend into the tongue anlagen before breaking up into their fine terminal endings (fig. 4, and compare with fig. 5 of Pearson, '39).

In the 14-day, 21-hour embryo. At this stage there is an increase in the number of multipolar cells of the nuclear column and a greater distribution of the terminal branches within the tongue. The two hypoglossal roots pass out of the developing cranial cavity through separate canals in the base of the developing skull. Due to an increase in growth of the nerve and of the surrounding structures, the hypoglossal trunk does not extend quite to the ventral limit of the nodose ganglion before turning rostromedially but swings forward along its lateral surface. The combined cervical branches retain their earlier relations with the ganglion, however, passing beneath it and then curving slightly rostralward to meet the hypoglossal nerve anterior to the ganglion (fig. 3).

In the 15-day, 6-hour embryo. The cellular characteristics of the central gray column are practically the same in embryos of this age as in the previous series. The caudal limit of the cell column can now be defined through a change in cell type at the transition from the medulla oblongata to the spinal cord, the cells of the somatic efferent column of the medulla oblongata being large and surrounded by a light neuroglia, and the cells immediately caudad to them being slightly smaller and the neuroglia less evident. Except for an increased distribution within the tongue, the peripheral relations are the same as for the previous stage (fig. 4).

In the 16-day, 6-hour embryo. At this age there is an indication that the hypoglossal nuclear column is divided into cell groups. The differentiation is not complete enough, however, to locate any specific group throughout its extent within the column.

Peripherally the terminal branches can be traced to the muscle fibers. No special end-organs were found in this or subsequent stages in the available material but only the branching ends of the nerves contiguous to the muscle cells.

In the 17-day embryo. The nuclear grouping is more pronounced in this embryo but still not complete. The ventrolateral and ventromedial groups are clearly distinguishable in the cephalic portion of the nucleus, and in its caudal portion there is an accumulation of cells lateral to the main mass of the column, indicating the formation of the dorsolateral cell group. However, there are many scattered cells, between the two portions of the nucleus, which appear to be shifting 
laterally into the dorsolateral group. The column is no longer continuous caudally with the spinal cord gray.

In the 20-day embryo. Definite subdivision of the hypoglossal nuclear group into three portions has occurred. The dorsolateral group is present only in the caudal portion and the ventrolateral only in the cephalic half, but the ventromedial group of cells is continuous throughout the rostrocaudal extent of the nucleus.

In the 25-day embryo. The majority of the hypoglossal neurons are now multipolar. All those studied either presented three (or more) processes or by their shape were indicative of multipolarity.

In the 1-day-old rabbit. Most of the cells of the hypoglossal nucleus have greatly increased in size and in number of processes and closely resemble ventral horn motor neurons. Some few neurons, particularly within the ventrolateral cell group, still show the irregularly oval shape characteristic of the embryo.

Peripherally the general relations are practically the same as those described for the 16-day, 6-hour embryo. Growth and general development have caused some modification of the peripheral course, such as the crossing of the hypoglossal nerve lateral to the vagus above the nodose ganglion.

In the 6-day-old rabbit. By this time the neuroglia does not stain so deeply in this region as does that of the embryo. Fibers from the ventromedial and dorsolateral nuclear groups contribute to both hypoglossal roots, but fibers arising in the ventrolateral group pass only to the cephalic root. Very few of the most rostral cells of the dorsolateral cell group distribute to the cephalic root, the majority of its neurons joining the caudal root.

The hypoglossal nucleus in the adult rabbit. The hypoglossal nucleus in the adult rabbit has the same relations and position as in the older embryos. It lies in the medulla oblongata, ventrolateral to the fourth ventricle and close to the raphé, and is the caudalmost nuclear group of the somatic efferent cell column (fig. 15). In reconstructions (fig. 20 ) the nuclear mass appears fairly irregular in outline and has its greatest diameter slightly in front of the middle of its long axis. Its rostral termination is rather more abrupt than its caudal limit. From a level $1.3 \mathrm{~mm}$. in front of the caudalmost fibers of the pyramidal decussation, the hypoglossal nucleus extends forward for $5.05 \mathrm{~mm}$., its cephalic tip being some $0.3 \mathrm{~mm}$. caudad to that of the dorsal efferent nucleus.

The hypoglossal nucleus of the rabbit is readily divided into the three cell groups, discussed for the carnivores by Ariëns Kappers, Huber and Crosby ('36, p. 581). As in carnivores, the ventromedial gray extends throughout the length of the nucleus, the ventrolateral 
group is found only in the cephalic half, and the dorsolateral group is confined to the caudal fifth and becomes lateral to the ventromedial cell group as it is followed forward. Further grouping was not studied in detail, but at certain levels it was clearly evident that the hypoglossal nucleus of the rabbit is divisible into groups similar to those of the anteater or the rat as presented by Stuurman ('16).

In its caudal part the hypoglossal nucleus is almost in contact with the dorsal efferent nucleus, which lies dorsal to it at this level, but this relationship changes farther forward, with the appearance of the nucleus intercalatus (Staderini, 1894) between the hypoglossal and dorsal efferent nuclei (fig. 10). As the nucleus intercalatus increases in size, the dorsal efferent nucleus shifts farther dorsolaterally. The nucleus intercalatus retains a dorsolateral relation to the hypoglossal nucleus (fig. 15) from the caudal appearance of the former to the rostral limit of the hypoglossal gray.

Ventrolateral to the hypoglossal nucleus throughout its length, but more evident at some levels than at others, is the nucleus of Roller (Roller, 1881, and fig. 10). An irregular column of small, reticular neurons (medial reticular nucleus of fig. 9) lies medial to the rostral part of the hypoglossal nucleus. In the periventricular gray just rostral to the hypoglossal nucleus are the nucleus praepositus and nucleus funiculi teretis, the former apparently a direct continuation of the medial reticular gray discussed above.

In all the rabbit material used none of these nuclear groups, discussed as contiguous to the hypoglossal nucleus, appeared to contribute root fibers to the hypoglossal nerve. Berkelbach van der Sprenkel ('24) believed he could trace neuraxes from the cells of the nucleus of Roller into this root, as did Roller (1881), and that these were distributed to the ganglion cells on the walls of blood vessels. Von Bechterew (1899) and Edinger ('08) also regarded the nucleus of Roller as a general visceral efferent center, but Vincenzi (1884) and von Kölliker (1896), as well as various other observers, could not find this contribution to the hypoglossal root. It is generally agreed that the nucleus funiculi teretis and the nucleus praepositus do not contribute to the hypoglossal root.

Internuclear connections between the hypoglossal nucleus and the nuclear groups surrounding it are rather abundant. These appear to be processes of the cells of the nucleus praepositus, the nucleus of Roller, the nucleus funiculi teretis, and the other reticular nuclear groups in this area, which end in relation with the cells of the hypoglossal nucleus.

The cells of the hypoglossal nucleus are large, multipolar elements with flaky Nissl substance and a rather dense neurofibrillar reticulum. 
Their neuraxes course ventrally through the medulla oblongata, medial to the inferior olive, and emerge on the ventral surface of the brain stem. The dendrites for the most part are quite short, although some processes from more medially located neurons of the ventromedial cell group extend into the region of the raphé. Whether they enter the homolateral or contralateral medial longitudinal fascieulus or cross to other centers on the opposite side of the medulla oblongata is uncertain.

\section{The abducens}

In the 11-day embryo. At this stage the abducens nerve has its origin from bipolar neurons located in the common efferent cell column described previously (see p. 86). They are confined to a single neuromere ( $\mathrm{D}$ of fig. 1a) situated rostral to that giving origin to the glossopharyngeal nerve and caudal to that from which originates the facial nerve.

Neuraxes of these cells course ventrally and combine into numerous small fascicles which emerge on the ventral surface of the brain stem at all levels between the emergent facial and glossopharyngeal nerves, but medial to them. After emergence, they immediately turn forward and show slight evidence of combining into a single trunk. The loosely arranged nerve continues rostrally for a short distance toward the region of the primitive cavernous sinus, giving off, all along its course, fine filaments which enter the surrounding mesenchyme.

In the 12-day embryo. The central cells of origin of the abducens are still undifferentiated in the common efferent cell column, but are more numerous and slightly larger than the corresponding neurons of the 11-day material. Peripherally the nerve is larger and extends into the mesenchyme which will eventually differentiate into the extrinsic eye-muscles (fig. 3). Fine filaments leave the nerve along its course to enter the surrounding mesenchyme.

In the 13-day, 2-hour embryo. The cells of origin are differentiating into a distinct nuclear group (fig. 22a), which is not so well defined as the hypoglossal column at this age. The forming abducens nucleus lies lateral and ventrolateral to the developing internal genu of the facial nerve throughout the longitudinal course of these fibers. Caudally the nucleus is not distinguishable from the cells of origin of the facial nerve, which are undergoing their neurobiotactic migration and, at this age, surround the dorsal and dorsolateral cells of the abducens nucleus in its caudal portion (fig. 22a). In the caudal part of the gray giving rise to the facial rootlets are a few cells which apparently give rise to aberrant abducens fibers, which do not join the abducens root but end in the mesenchyme ventral to the brain stem (fig. 26). 
Bremer ('08) found that the abducens nerve frequently has a number of such small rootlets and a caudal continuance of its nucleus in embryos. Bremer ('21) stated that in cases in which they are sufficiently developed they pass into museles of the head region or anterior spinal musculature. As pointed out by Streeter ('12) and by Ariëns Kappers, Huber and Crosby ('36), these roots are mostly aberrant. The neurons of the differentiating abducens nucleus are still of the bipolar type but show an increase in size and neurofibrillar content as compared with those of the 12-day-old embryo.

Peripherally the abducens nerve fibers are more compactly arranged and come into very close relationship with the terminal branches of the oculomotor nerve, which has invaded the mesenchyme about the developing eye. The fine branches from the abducens nerve, which enter the mesenchyme along its course, are still present but are confined more or less to the region of the primitive cavernous sinus.

In the 14-day, 6-hour embryo. The abducens nucleus is well differentiated from the surrounding structures excepting caudally, where the migrating special visceral efferent neurons of the facial nerve are scattered along its dorsal and lateral borders. Its position remains the same as in the 13-day, 2-hour stage, and its neurons are still scattered rostrocaudally throughout the length of the horizontal limb of the genu of the facial nerve. A few cells are found among the emergent fascicles of the facial root in the most rostral region of the abducens nuclear group. Caudally there are cells of this nucleus among the ventrolaterally migrating facial neurons and ventral to them.

Some few of the abducens neurons are multipolar by this stage, although the majority still appear round or oval in outline. The processes of the cells are well developed and can be followed for quite a distance. The root fibers leave the nuclear mass on its ventromedial aspect, course toward the midline for a short distance, and then turn ventrally to emerge from the ventral surface of the brain stem. The dendrites of the cells are distributed dorsolaterally toward the vestibular areas, and laterally and ventrally there are intereonnections (largely through the peduncle of the superior olive) between this nucleus and the superior olive. Strong bundles of fibers arising from the medial and lateral vestibular nuclei pass dorsal to, and in some cases directly through, the abducens nucleus, as they course toward the medial longitudinal fasciculus (fig. 26). Accompanying the medially directed fibers from the lateral vestibular nucleus are fine fascicles which originate in the nucleus of the spinal root of the trigeminal nerve and appear to end among the cells of the abducens nucleus.

From the caudally located cells of the abducens nucleus fine rootlets course directly ventrally and emerge caudal to the main group 
of the abducens fascicles. In one series studied, two such roots are present on the same side, the more rostral of which becomes a part of the abducens nerve while the more caudal courses lateralward and caudalward to join the glossopharyngeal nerve at the medial aspect of the petrous ganglion. Whether this root is distributed with the pharyngeal branches of the glossopharyngeal nerve to branchiomeric muscle as, according to Bremer ('21, see p. 100), is sometimes the case, or whether it ends among the glossopharyngeal fibers as an aberrant branch, it is impossible to determine in this instance since the fibers are not distinguishable from those of the glossopharyngeal nerve.

In the region of the termination of the abducens nerve, in the mesenchyme of the developing eye-muscles, anastomotic branches are found between this nerve and the oculomotor terminal fibers, as well as fine branches from the inferior portion of the ophthalmic division of the trigeminal nerve. Fine branches still leave the root as it courses through the mesenchyme around the cavernous sinus.

In the 14-day, 21-hour embryo. The abducens nucleus has shifted into a more dorsolateral position and lies more lateral than ventrolateral to the horizontal portion of the internal genu. Caudally the nucleus is now distinguishable from the migrating special visceral efferent neurons of the facial nerve inasmuch as the caudally located cells of the younger stages are collecting rostrally into a main nuclear mass. The abducens nucleus, throughout its extent, is characterized by a light neurogliar background. The neuraxes from the caudally located neurons course ventrally through the brain stem in four to five fine fascicles and, upon emerging, join into a single root (fig. 26) which, instead of turning rostralward, continues ventrolaterally toward the petrous ganglion of the glossopharyngeal nerve. This root ends, however, aberrantly in loose mesenchyme, before reaching the glossopharyngeal nerve. Anastomoses of the abducens nerve with the oculomotor and ophthalmic divisions of the trigeminal are again observed about the developing eye. One fine branch from the abducens is also traceable into the developing ciliary ganglion. A few aberrant branches still leave the root as it courses through the mesenchyme about the cavernous sinus.

In the 15-day, 6-hour embryo. The caudalmost neurons of the abducens nucleus still lie ventral and ventromedial to the cells of origin of the facial nerve, with their fine rootlets extending into the loosely arranged mesenchyme ventral to the brain stem. A few of these rootlets turn rostralward to join the main bundle of the abducens nerve but the majority of them end aberrantly. Except for an increased number of multipolar neurons the abducens nucleus appears much the same as that of the 14-day, 21-hour embryo. 
In the region of the cavernous sinus fine aberrant branches are again evident. The abducens root is in close association with the sympathetic (thoracico-lumbar) plexus about the internal carotid artery, and a few of the branches of this system appear to accompany it for a short distance, and then to turn ventrolaterally toward the sphenopalatine ganglion. Anastomotic fascicles persist between the terminal branches of the abducens and oculomotor nerves in the mesenchyme about the eye.

In the 16-day, 6-hour embryo. The abducens nucleus is becoming more compactly arranged due to a rostral migration of the caudally located cells of the younger series. Very few neurons remain in the area about the caudal end of the horizontal limb of the internal genu (see p. 97). Aberrant abducens rootlets still course ventrally through the medial cells of the ventral facial nucleus, then emerge from the ventral surface of the brain stem and end in the mesenchyme beneath it. These rootlets can be traced centrally to the dorsal boundary of the ventral facial nucleus, but are lost among the dorsomedially directed processes from the neurons of this nucleus. Their location caudal to the emerging abducens nerve indicates that some of the primitively caudally located cells of the abducens have not shifted rostrally, but whether those rootlets arise from cells located as far dorsal as the position of the abducens nucleus or from ventrally shifting cells from this nuclear mass it is not possible to determine in the available material.

Peripherally terminal abducens fascicles can be traced into the differentiated lateral and medial heads of the lateral rectus muscle. An anastomotic branch is found between the terminal branches of the abducens and the oculomotor nerves.

In the 17-day embryo. The nuclear mass has become more compact at this stage. Some of the more caudally located roots swing slightly backward as they leave the nucleus, indicating the rostral migration of certain cells of this nucleus during development. No aberrant branches are found. Peripherally the distribution of the abducens is the same as in the 16-day, 6-hour embryo excepting that a fine terminal branch again is traceable into the ciliary ganglion as was the case in the 14-day, 21-hour embryo. However, this union with the ciliary ganglion is probably not formed by neuraxes originating in the abducens nucleus but by sympathetic (thoracico-lumbar) fibers which have accompanied the abducens nerve from the plexus about the internal carotid artery, with which it is in close relation in the region of the cavernous sinus.

In the 20-day embryo. All of the neurons of the abducens nucleus appear multipolar by this stage. The cells have collected into a com- 
pact nuclear group toward the rostral end of the primitive gray column of the younger embryos and the entire group of cells has shifted farther dorsolaterally so that its present position is approximately that found in the adult rabbit (fig. 20 ; see also Ariëns Kappers, Huber and Crosby, '36, fig. 305, p. 609). The neuraxes of these cells leave the nucleus on its ventromedial aspect to continue around the ventral border of the horizontal limb of the genu of the facial nerve toward the raphé and then to turn ventrally, and at the same time somewhat laterally and rostrally, as they course toward their superficial origin from the brain stem. As a result of the accumulation of the abducens cells toward the rostral pole of the nucleus and the slight rostral course of the abducens root, the superficial origin of the nerve is approximately at the same level as that of the facial nerve. Several fine
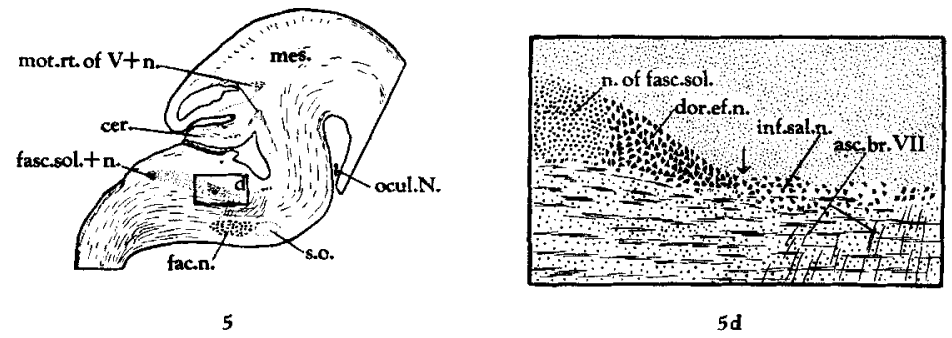

Fig. 5 A drawing of a sagittal section through the brain stem of a 20-day rabbit embryo, intended to serve for general orientation and as a key drawing for figure 5d. Pyridine silver. $\times 7$.

Fig. 5d A longitudinal (but slightly oblique) section through the general visceral efferent column of the 20-day rabbit embryo. The location of the area drawn is indicated in figure 5. Note particularly the region of separation between the dorsal efferent nucleus and the inferior salivatory nucleus. $\times 52$.

aberrant rootlets are found again at this age. Some of these emerge medial to the main root and are lost in the mesenchyme shortly after their emergence. Others leave the brain farther caudad, then turn rostrally toward the main root but end in the mesenchyme before reaching it. One fairly strong rootlet which emerges through the medial cells of the rostral pole of the facial nucleus makes several turns in the mesenchyme, at first swinging rostrally, then caudally, and finally coursing along the developing base of the skull. It penetrates the cartilage, continues toward the developing middle ear, and, just as it reaches the perichondrium lining this structure, turns laterocaudally to emerge from the cartilage in the jugular foramen. It then becomes incorporated with the glossopharyngeal nerve. Some of these aberrant branches can be traced to their cells of origin in the caudal 
part of the abducens nucleus; others are lost (fig. 29a), as they are followed centrally, at a horizontal level corresponding to that of the developing accessory abducens nucleus but medial to this nucleus. In the material available it is impossible to determine whether these fibers originate from the cells of the abducens nucleus or from the more laterally located cells of the developing accessory abducens nucleus.

The accessory abducens nucleus (fig. 29a) at this age consists of a relatively few, scattered cells extending rostrocaudally from the middle of the facial nucleus (but dorsomedial to it) to become continuous with the ventromedial cells of the motor trigeminal nucleus. Further consideration of this nucleus and of its relations is to be found under the discussion of the 1-day-old rabbit.

In the 22-day embryo. The abducens nucleus has the same characteristics as that of the 20-day embryo. A greater number of cells are found in the region of the accessory nucleus, but again it has not been possible to trace the processes of these cells into either the facial or the abducens root in the material available. Concentration of the cells of the main abducens nucleus toward the rostral part of the horizontal portion of the internal genu of the facial nerve and the slightly rostral course of the root fibers are again evident. The abducens nerve emerges at the same level as does the facial nerve but medial to the latter.

In the 1-day-old rabbit. The abducens nucleus has now become quite compactly arranged and its constituent cells have the appearance of adult neurons. Medial to the nucleus, and mediocaudally among the most medial fibers of the facial nerve as they enter the caudal portion of the genu, are small, scattered neurons comparable to those described about the hypoglossal nueleus. These small-celled reticular masses were more closely associated in position with the special visceral efferent cells of the facial before their ventrolateral migration, but appear to have shifted somewhat ventrally by this stage and are continuous caudally with the nucleus praepositus. The number of such small reticular cells varies greatly from level to level.

The accessory abducens nucleus (fig. 29a), as recognized and Iocated by Terni ('22), is present and is well developed and compactly arranged. Van Gehuchten (1899), Winkler and Potter ('11), Preziuso ('24), Addens ('33) and others have termed this nuclear group the accessory nucleus of the abducens nerve. Van Valkenburg ('10), Ariëns Kappers ('20) and others refer to this group of cells as the dorsal facial nucleus. In the material used for this study is has been impossible to trace neuraxes from these cells definitely into either the abducens or the facial roots. Fibers in the region of the nucleus, but not directly from the cells composing it, course dorsomedially toward 
the genu of the facial root and some turn more medially as if they were about to arch into the emerging abducens root (fig. 16) similarly to those figured by Terni ('22, fig. 15) for Mus rattus. However, they do not appear to become incorporated with any of the emergent fascicles of this nerve as it courses toward the periphery. In fact, some of the fibers in question continue medially toward the raphé. Thus, whether these dorsomedially directed fibers are neuraxes from these cells and their connections with the cell body are not impregnated in our material, or whether they are part of the peduncle of the superior olive, which they closely resemble in size and staining characteristies, cannot be determined at this time. As mentioned in the discussion of the 20-day embryo (p. 101), the so-called accessory abducens nucleus extends into the region of the motor nucleus of the trigeminal nerve. At this age the rostral end of this nuclear column actually becomes a part of the motor trigeminal nucleus, and neuraxes from some of the cells of the so-called accessory abducens nucleus, which are caudal to the trigeminal nucleus, as well as those ventromedial to its caudal portion (fig. 29a), contribute to the motor root of the trigeminal nerve (see p. 141). Possibly still other more caudally located neurons of the column so contribute. It is probable that some of the cells of this group constitute a part of the trigeminal nucleus of the adult and the remainder compose the adult accessory abducens nucleus. Certainly further study, based on additional material, is essential to determine the complete distribution of this cell mass.

An increased number of abducens fibers enter the two heads of the lateral rectus muscle. Otherwise the abducens nerve terminates here as it did in the 17-day embryo.

In the 6-day-old rabbit. The only change observed for this age is the loss of the embryonic character of the neuroglia.

The abducens nucleus in the adult rabbit. The abducens nucleus is the most laterally located of the cell groups composing the somatic efferent cell column (fig. 20). Its position (the same as that described for the older embryos, see p. 101) is lateral to the horizontal limit of the internal genu of the facial nerve. It is located ventrolateral to the fourth ventricle, dorsolateral to the medial longitudinal fasciculus, and dorsomedial to the spinal root of the trigeminal nerve and its nucleus. Dorsal to it, and quite closely related, is the medial (or principal) vestibular nucleus and laterally and dorsolaterally is the lateral vestibular nucleus. The caudal portion of the abducens nucleus is in the same horizontal plane as are the rostralmost cells of the more ventrolaterally placed efferent facial gray.

The abducens nucleus is nearly uniform in its mediolateral and ventrodorsal diameters and its rostrocaudal extent is $1.15 \mathrm{~mm}$. In 
cross section the nucleus appears nearly circular-thus the three dimensional aspect is somewhat cylindrical. In reconstruction (fig. 20) it is found to be most irregular on its medial aspect.

The characteristic neurons composing the abducens nucleus are of the large, somatic efferent type similar to those of the hypoglossal nucleus (p. 95). Among such neurons are two other cell typesmedium-sized cells and small granule cells. The medium-sized cells, which are relatively few in number and of uniform distribution throughout the nucleus, resemble the small reticular elements scattered ventrally and, to some extent, the medium-sized cells of the medial vestibular nucleus located dorsally. The small cells are not so uniformly distributed throughout the nucleus but appear in various sized clusters among the most medial cells and along the medial aspect of the nucleus close to, and slightly ventral to, the longitudinally coursing fibers of the facial genu. These groups become more numerous as the caudal limit of the nucleus is approached and can be followed caudally into the nucleus praepositus. Such small cells are similar to those discussed in conjunction with the special visceral efferent cells of the facial nerve for the younger embryos (see pp. 130 and 134). In the silver preparations the root of the abducens appears to come only from the large cells of this nucleus, as has been proved experimentally by Fuse ('12). Fuse also stated that the ventricular portion, which is probably homologous with the small-celled groups ventromedial to the main nuclear mass, is present in the mole, in which a true abducens nucleus is lacking.

Visceral Efferent Component. Its Central and Peripheral Development

\section{The vago-accessory}

In the 11-day embryo. At this stage the vago-accessory fibers have their origin from three sources-the primitive efferent cell column, the developing accessory cell column in the cervical cord, and the primitive ganglia of the root. As stated earlier (see p. 86), the primitive efferent cell column is continuous rostrally with the cells of origin of the glossopharyngeal nerve (fig. 1a) and caudally with a similarly located cell column of the spinal cord. The oval, bipolar cells contributing to the vago-accessory nerve are confined to the most caudal neuromere ( $F$ of fig. 1a) of the brain stem, in the most lateral part of this column. Those cells giving rise to the hypoglossal nerve are located medially within the column. There is no differentiation between vagal and hypoglossal neurons at this age except that the lateral cells send their neuraxes laterally to emerge from the lateral surface of the brain stem, and the medially placed cells send their processes ventrally. Thus this material, as well as that of several other observers 
(Mesdag, '09 ; Bok, '15; Tello, '22; Windle, '33; and others), indicates that the somatic efferent cells are the more medially located and the visceral efferent cells are the more laterally located neurons within the common efferent column. The processes of the cells of origin of the vago-accessory nerve course dorsolaterally through and ventral to the undifferentiated, longitudinally coursing fasciculus solitarius and to the spinal root of the trigeminal nerve (fig. 8) to emerge from the lateral surface of the brain stem.

The second group of cells contributing to the vagus nerve, the primitive accessory cell column, is located in the upper seven segments of the cervical cord. It has not been possible to determine the exact cells contributing to the roots of the spinal accessory nerve in the material available, but, by tracing the roots centrally toward their cells of origin, the approximate location of such cells, lateral to the central canal and just ventral to the plane of the sulcus limitans (fig. 6), can be determined. The neurons in this area, a part of the efferent column of the spinal cord (see Pearson, '38), are all of the rounded, bipolar type with small amounts of neurofibrillar material at their peripheries. Their axons accumulate into fine fascicles and course dorsally into the afferent area of the spinal cord (fig. 6). Just ventral to the entering sensory roots of the spinal nerves, these fascicles turn lateralward to emerge from the dorsolateral surface of the spinal cord under cover of the dorsal root ganglia. From their superficial origin these rootlets course slightly ventralward and then turn rostralward to combine into a single nerve with their fellow components of higher or lower levels. The nerve

Fig. 6 A transverse section through the upper portion of the spinal cord of an 11-day rabbit embryo. Note particularly the position of the eells of origin and the course of the spinal accessory nerve. Pyridine silver preparation. $\times 85$.

Fig. 7 An oblique section through the medulla oblongata of a 14-day, 6-hour rabbit embryo. At this stage the visceral efferent column, as represented by the nucleus of the spinal accessory nerve, is separated from the somatic efferent column. Pyridine silver preparation. $\times 56$.

Fig. 8 A transverse section through the medulla oblongata of a 13-day, 2-hour rabbit embryo. Note the relations of the fasciculus solitarius and its nucleus, which at this stage are separated from the general afferent gray, and the positions of the somatic and visceral afferent nuclear columns. Pyridine silver preparation. $\times 36$.

Fig. 9 A transverse section through the caudal region of the medulla oblongata of a 14-day, 6-hour rabbit embryo. The figure illustrates particularly the initiation of differentiation of the special visceral efferent column. Pyridine silver. $\times 33$.

Fig. 10 A transverse level similar to that of figure 9 but from a 14-day, 21-hour rabbit embryo. This illustration shows especially the further differentiation of the special visceral efferent column to form a primordial nucleus ambiguus. Pyridine silver preparation. $\times 33$. 
runs forward along the dorsolateral surface of the spinal cord, medial to the dorsal root ganglia. In the caudal region of the brain stem it begins to eurve ventrally and gradually arches into the vago-accessory trunk. The roots of the bulbar portion of the accessory nerve, after emerging from the lateral surface of the brain stem, turn ventrally and, joining the spinal accessory portion on its dorsomedial aspect, accompany it ventrorostralward to join with the centrally directed roots of the vagus nerve in forming the vago-accessory nerve.
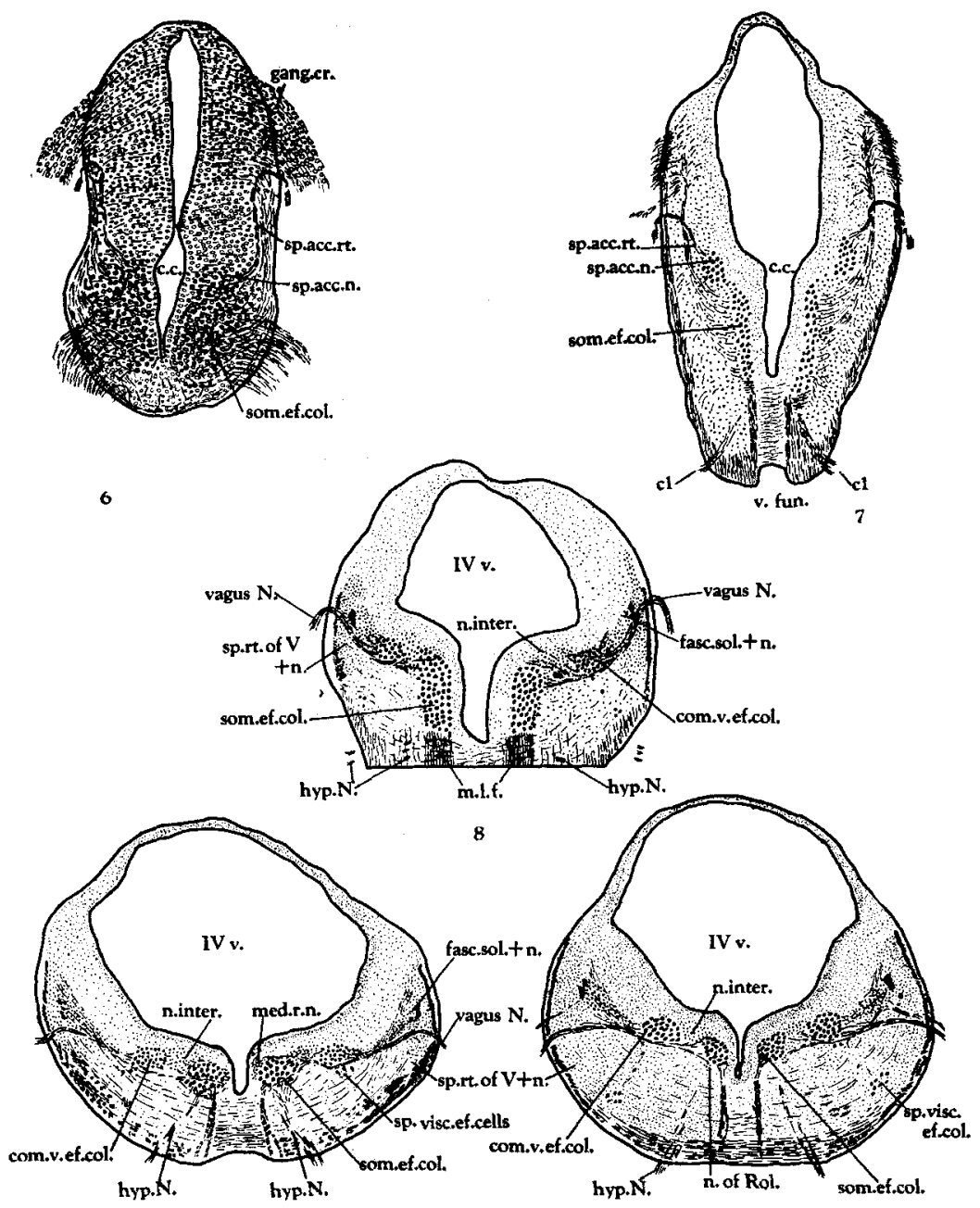
The third group of cells contributing to the vago-accessory complex, the primitive root ganglia, is composed of bipolar elements scattered along the nerve root. The more primitive of these cells are as yet a part of the ganglionic crest at the stage in which the more mature cells are migrating caudad along the trunk. A grouping of the more caudally located neurons indicates the beginning of the formation of the nodose ganglion (fig. 2).

From the region of the primitive nodose ganglion the combined trunk, including the peripherally directed processes of the ganglion cells, courses along the dorsal wall of the anterior cardinal vein and then runs ventral to it, having passed around its medial wall. Farther caudad fine, bifurcating, knobbed endings appear on some of its fibers as the bundle lies lateral to the developing pharynx. It terminates slightly behind this plane in the region lateral to the primitive larynx (fig. 2).

In the 12-day embryo. In the 12-day as compared to the 11-day embryo there is very little change in the differentiation of the common efferent cell column. However, there are more and larger cells in this column and their centrally directed processes are better developed. There is no indication of further differentiation between the medial (somatic) and lateral (visceral) cells of the common column. The spinal accessory nerve is again traceable to the seventh cervical segment (fig. 3) with its undifferentiated cells of origin located just medioventral to the cells of reception for the dorsal roots of the spinal nerves.

The fasciculi of the bulbar portion of the accessory nerve course rostrally together with its spinal root to the level of the now differentiating jugular ganglion, and then the vago-accessory complex turns ventrocaudally to pass through and around the differentiated nodose ganglion. The spinal portion is quite distinguishable throughout its extent and lies slightly removed, dorsocaudally, from the jugular ganglion and close to the dorsolateral aspect of the nodose ganglion (fig. 3). The relations of the nerve trunk to the anterior cardinal vein are the same as those given for the 11-day embryo. The first branch from the vago-accessory trunk is from the spinal accessory portion. This branch distributes to the mesenchyme lateral to the anterior cardinal vein and to the hypoglossal nerve (fig. 3) but ventromedial to the somites. From the nodose ganglion the vago-accessory nerve courses caudad in close relationship with the alimentary canal, the bulbar accessory portion retaining a ventrolateral position within the trunk. In the upper pharyngeal region, the combined trunk lies dorsolateral to the pharynx and then swings slightly ventromedialward (fig. 3) into a position ventrolateral to the oesophagus. In the region 
of the developing stomach, the right vagus courses dorsalward and terminates in the mesenchyme about the dorsolateral wall of this structure. The left vagus retains a ventrolateral relationship to the oesophagus and to the rostral portion of the stomach and ends along the ventrolateral stomach wall after having given off numerous, fine branches into the mesenchyme between this organ and the heart (fig. 3). Other branches from the vago-accessory trunk (in order of their origin) are: (1) the pharyngeal branch from the dorsomedial portion of the trunk, thus of vagal origin; (2) the superior laryngeal branch, also from the dorsomedial portion of the trunk and of vagal origin; (3) the inferior laryngeal branch from the ventrolateral aspect of the trunk, and so from the bulbar accessory nerve; and (4) anastomosing branches from the right and left vagi along the ventral wall of the oesophagus. Within the mesenchyme among the fine terminal branches of the developing plexuses (fig. 3) are many sympathetic ganglion cells. These cells are particularly abundant in the mesenchyme along the dorsal and lateral walls of the oesophagus, but they are also found about the trachea and in the mesenchyme between the oesophagus and the developing heart.

In the 13-day, 2-hour embryo. The common visceral efferent cell column is differentiated in this embryo, being located ventrolateral to the fourth ventricle and dorsolateral to the hypoglossal nucleus (fig. 8). This nuclear column is continuous rostrally with the cells of origin of the glossopharyngeal nerve and caudally with a laterally located group of cells in the spinal cord.

The cells of the column are still of the bipolar type. In comparison with those contributing to the vago-accessory complex of the 12-day embryo, the neurons at this age show more processes and an increase in neurofibrils, which are still very evident at the periphery and lacking within the central region of the cells. The cells of origin of the spinal accessory nerve show some indication of column formation but the differentiation is not nearly so distinct for these as for the neurons contributing to the vagus and to the bulbar portion of the accessory nerve. The neurons of the spinal accessory column, some of which appear to be multipolar, also have an increased number of neurofibrils at their periphery.

The origin and the early part of the course of the spinal accessory root are similar to those described for the younger embryos but as the level of the medulla oblongata is reached this root swings somewhat more ventrally than in the younger series (compare figs. 2 and 4 ), so that it lies ventrolateral to the brain stem. Neuraxes from the caudal portion of the common visceral efferent column of the brain stem, the bulbar portion of the accessory nerve, run dorsolaterally through the 
medulla oblongata and through the caudal portion of the primitive nucleus of the fasciculus solitarius to emerge from the lateral surface of the brain stem. After emerging, these fibers pass rostrally in company with (but slightly dorsal to) the spinal accessory nerve to the region of the jugular ganglion. Neuraxes from the more rostral portion of the common visceral efferent column, contributing to the vagal portion of the vago-accessory complex, course dorsolaterally through the primitive nucleus of the fasciculus solitarius and then emerge from
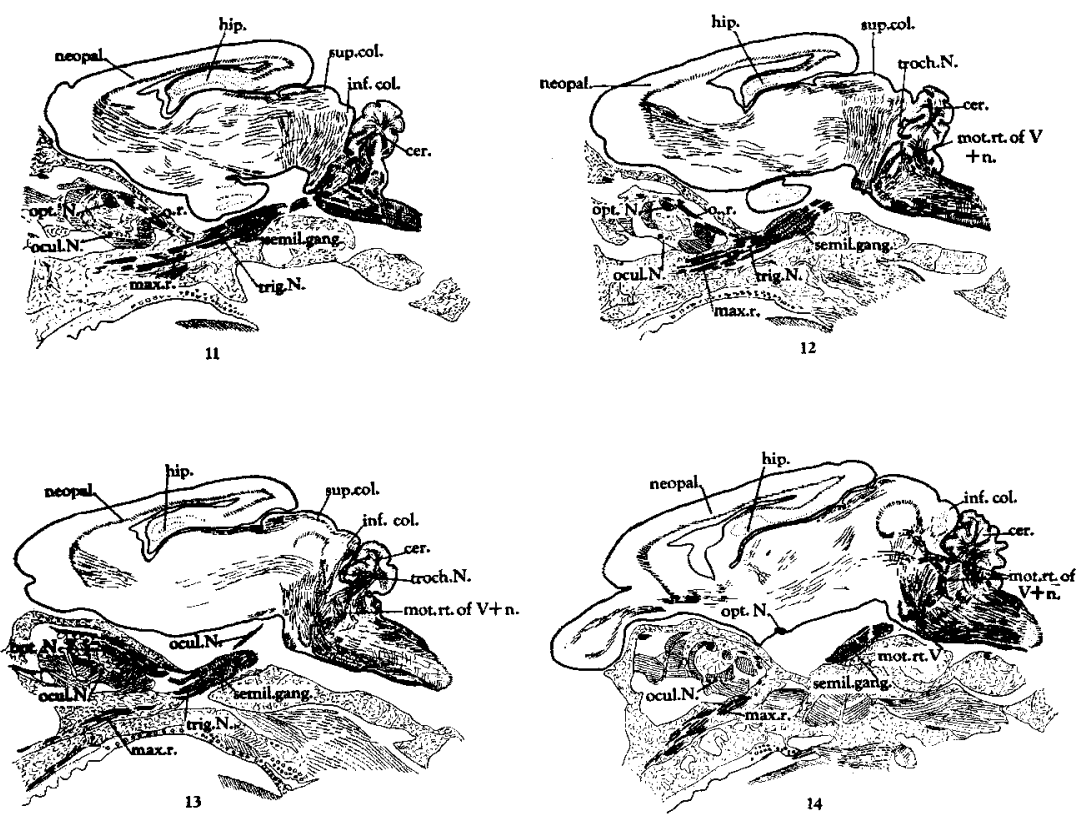

Figs. 11 to 14 These figures illustrate various sagittal levels drawn from a whole-head series of a 1-day rabbit. Figure 11 is the most lateral of the group, with the succeeding levels medialward arranged in order. This series of figures is designed to show certain phases of the peripheral distribution of the trigeminal nerve. Pyridine silver. $\times 6$.

the lateral wall of the brain stem in close association with the centrally directed processes of the ganglion cells. After emerging they turn ventrocaudad and combine into two or three bundles just rostral to the bulbo-accessory root (fig. 4). Continuing this caudal course, the vagal roots filter through the jugular ganglion and, at a level through the caudal portion of this ganglion, the three components of the vagoaccessory complex are distinguishable; the spinal accessory nerve is dorsal, the ganglion with the vagal fibers in its midst is ventral, and 
the bulbar accessory nerve is placed between the two and close to the dorsal wall of the ganglion.

The first fascicles given off from this vago-accessory complex, as it is followed caudad from the inferior portion of the jugular ganglion, form the auricular branch which runs ventrolaterally to distribute lateral and posterior to the developing ear (fig. 4). Arising in common with the auricular branch, and in part from the anterior portion of the vagal root, is the meningeal branch which extends dorsomedialward toward the brain. Between the jugular and nodose ganglia, the bulbar accessory nerve swings to the lateral side of the vagal trunk, but the spinal accessory nerve retains its dorsal relation to the bulbar root so that, at the level of the nodose ganglion, the bulbar root of the accessory nerve is lateral and the spinal accessory nerve is dorsolateral to the ganglion. A short distance caudad to the nodose ganglion the spinal accessory nerve leaves the main trunk and swings dorsolaterally into the mesenchyme, lateral to the anterior cardinal vein, to terminate in quite close association with the end branches of the second cervical nerve. The pharyngeal branch arises from the medioventral portion of the vagal root at the level of the second cervical nerve, and the laryngeal branches originate slightly farther caudad. The inferior laryngeal nerve is relatively small in comparison to the superior laryngeal (fig. 4), but there are clear indications that the superior is from the vagus and the inferior from the bulbo-accessory nerve. The superior laryngeal comes off of the main trunk as a comparatively strong, single branch, but the inferior arises as three relatively fine branches. Immediately below the origin of the superior laryngeal nerve there is a plexus formed by branches from the same part of the trunk that gives rise to this nerve. Whether this plexus, which is the rostral part of the oesophageal plexus, is of vagal or of bulbo-accessory origin cannot be determined in the available material.

As the two vagi descend along the anterolateral walls of the oesophagus, numerous anastomoses between them are evident and fine terminal branches are distributed into the developing musculature of the oesophagus. Fine branches from both vagi terminate ventrally about the trachea and, farther caudad, between the bronchi of the lungs. Some of these ventrally directed fibers (particularly those from the left vagus) continue beyond the region of the trachea toward the developing heart. The right vagus nerve lies dorsolateral to the developing stomach and the left, which is the larger of the two nerves at this age, swings over the anterolateral surface of this organ. As the left vagus approaches the stomach, a strong branch turns dorsally, and, after being joined by a bundle from the right vagus, passes for a short distance along the body wall toward the developing coeliac gang- 
lion (fig. 4). Numerous sympathetic ganglion cells are again present at this age in the mesenchyme among the plexuses, and the branches from the sympathetic trunk have invaded the mesenchyme lateral and dorsolateral to the region of distribution of the vagus (fig. 4). Near the nodose ganglion numerous fine filaments from the superior cervical ganglion extend toward the ganglia of the vagus but no actual connections have been found between the two systems.

In the 14-day, 6-hour embryo. Some of the cells of the common visceral efferent nuclear column, which is here better delimited than in the 13-day embryo, appear to be multipolar. This nuclear column is characterized by a light neurogliar background and is still continuous rostrally and eaudally with the cells of origin of the glossopharyngeal nerve and with the laterally placed cell column of the spinal cord respectively. In the caudal region of this cell column, the larger, better developed neurons are gathering ventrolaterally within it, indicating a beginning of the formation of the special and general visceral efferent columns (fig. 9). The cells of origin of the spinal accessory nerve, which have become in part multipolar and have increased in relative size (fig. 7), are differentiated into a definite nuclear column, which is also characterized by the light staining, embryonic neuroglia.

There is a fairly large eluster of ganglion cells along the spinal accessory nerve as it passes near the ventrolateral surface of the medulla oblongata. Dendrites of these cells enter the spinal accessory root and apparently are distributed peripherally with it. The eaudally directed neuraxes also become incorporated within the nerve but could not be traced to their termination. However, the rootlets composing this nerve, on being traced centrally into the cervical cord, do not all turn ventromedially toward the accessory cell column; some of them continue dorsomedially to end about the cells of the afferent area of the spinal cord along with the sensory root fibers. In addition to the ganglion on the spinal accessory nerve, which is probably Froriep's ganglion, there are many fibers which appear to be entering this root from the first dorsal root ganglion (fig. 4). Other small groups of ganglion cells are found among the emergent roots of the bulbar portion of the accessory nerve and their centrally directed processes are lost among the emergent efferent roots. Weigner ('01) reported many anastomoses between the spinal accessory nerve and the dorsal roots of the upper spinal nerves in man. He particularly emphasized those cases in which the dorsal root ganglion is incorporated within the accessory root. Streeter ('08) believed that the accessory as well as the vagus of the vago-accessory complex has sensory roots in the human embryo, and indicated a very close relation in position between the spinal accessory nerve and the dorsal root ganglion of the first cervical 


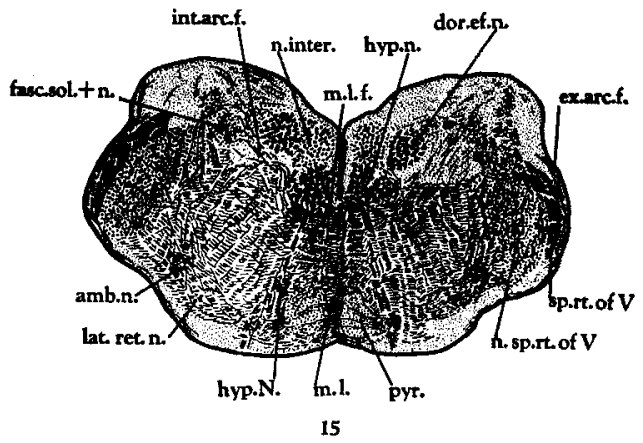

Fig. 15 A transverse section through the medulla oblongata of the 1-day rabbit, taken at the level in which the central canal is beginning to widen out into the fourth ventricle. The figure is designed to show particularly the nuclear groups associated with the hypoglossal and vagus nerves. Pyridine silver preparation. $\times 12.5$.

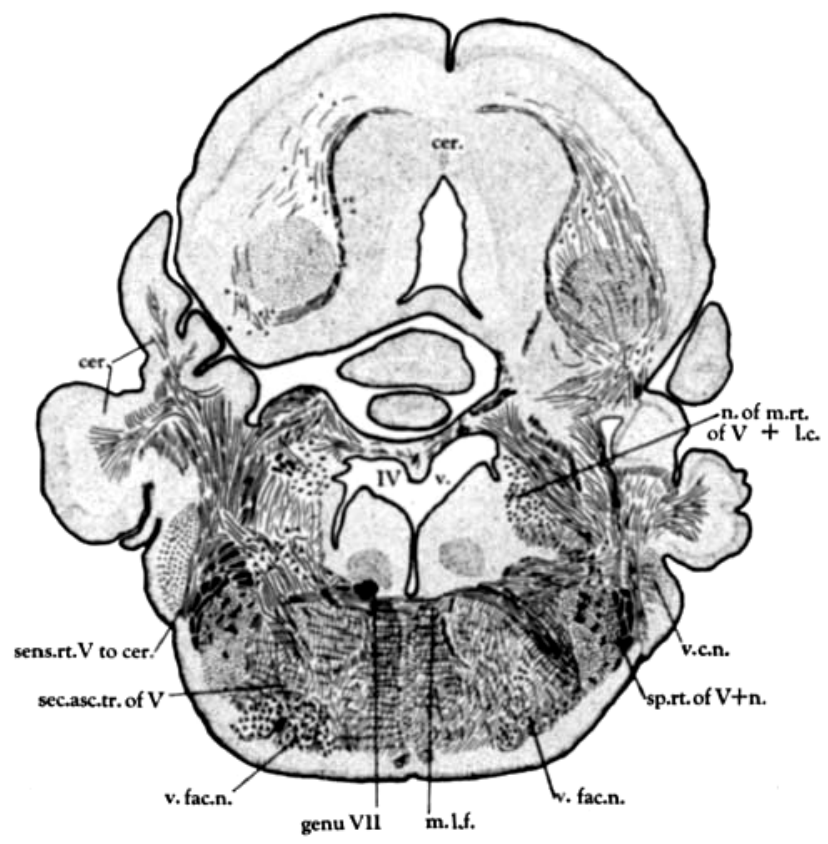

16

Fig. 16 A transverse section through the pons of the 1-day rabbit, taken at the level of emergence of the facial nerve. It illustrates particularly the ventral motor nucleus of the facial nerve. Pyridine silver. $\times 12.5$. 
nerve. Fahmy ('27) showed that ganglion cells are situated both intracranially and extracranially on the accessory nerve. Windle ('31), studying the cat embryo, found that sensory ganglion cells of the accessory nerve are partly along its root fibers and partly within the first dorsal root ganglion. He believed that they enter the caudal portion of the fasciculus solitarius and are mostly proprioceptive. Hinsey and Corbin ('34) found no proprioceptive fibers originating in the first four cervical ganglia in the cat.

In the peripheral distribution of the vago-accessory complex the meningeal and auricular branches are again given off at this age as a common root from the inferior aspect of the jugular ganglion. The pharyngeal branch originates at the level of the nodose ganglion and, from its medial aspect, courses medially toward the pharynx to inoseulate with the pharyngeal branch of the glossopharyngeal nerve. Thoracico-lumbar fibers have not as yet invaded this plexus but are scattered quite close to it in the surrounding mesenchyme. The spinal accessory nerve leaves the main trunk slightly caudad to the nodose ganglion and divides into two branches: the branch to the trapezius which courses dorsocaudally and somewhat laterally to be distributed in close relationship with branches from the third and fourth cervical nerves and the branch to the sternocleidomastoid which courses ventrocaudally and laterally and is distributed with branches from the second and the third cervical nerves.

The superior laryngeal branch, arising from the medial aspect of the root just below the nodose ganglion, is distributed dorsomedial to the developing larynx, and the inferior laryngeal branch is now recurrent. Originating from the lateral aspect of the nerve trunk, this branch courses ventromedially to cross in front of the vagus nerve, and then turns rostralward to be distributed in the ventroinferior region of the developing larynx. Along the lateral aspect of the oesophagus there is an increase in the complexity of the plexus. There are more branches directed ventrally about the trachea and bronchi and some of them pass well into the developing lungs. The more ventrally extending branches are coming into closer relationship with the heart but none have actually penetrated its walls. As the left vagus courses anterolateral to the stomach wall, it sends a strong branch dorsally around the cardiac end of the stomach which is joined by an equally strong branch from the right vagus nerve. This combined trunk extends ventrocaudally behind the stomach and breaks into numerous fine endings just ventral to the coeliac plexus. The terminal branches about the stomach wall are distributed well toward its pyloric end but no branches extend to the primitive duodenum. 
In the 14-day, 21-hour embryo. The special visceral efferent nuclear column is in process of formation. The larger, multipolar cells from the common visceral efferent column are migrating ventrolaterally, approaching the region of the nucleus ambiguus of the adult rabbit. In the caudal region of the brain stem many of the special visceral afferent cells are in position and others are found between this area and the common visceral efferent column (fig. 10). Farther rostrally there are fewer cells in their final position but those in the migratory

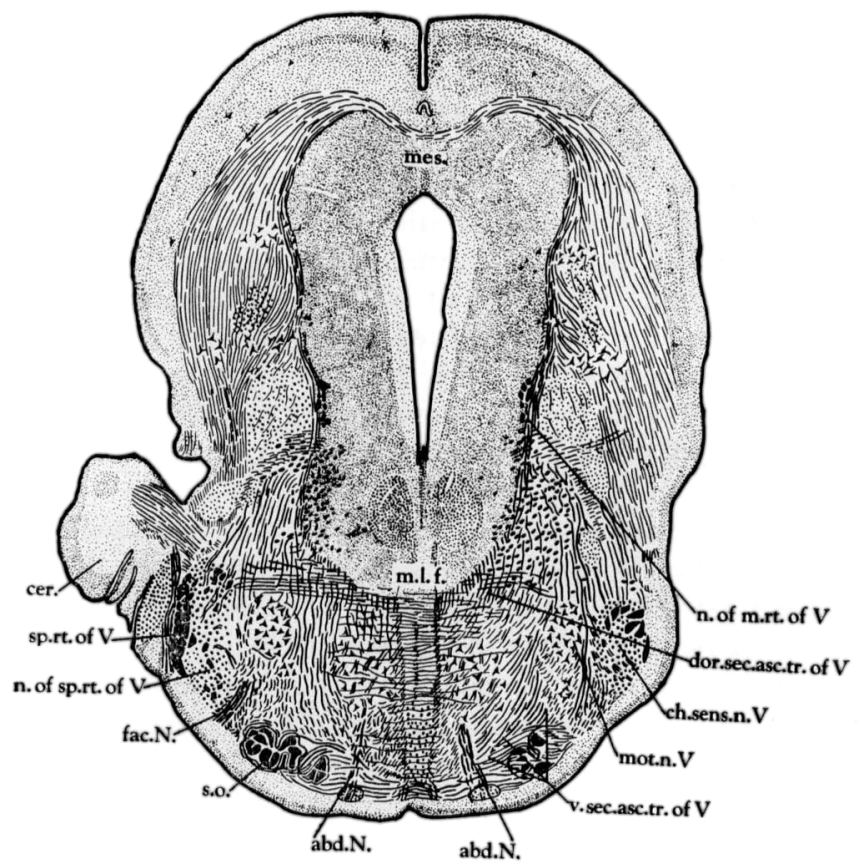

Fig. 17 A transverse section through the pons of the 1-day rabbit, taken slightly rostral to that illustrated in figure 16. Attention is called especially to the motor nucleus of the trigeminal nerve. Pyridine silver. $\times 12.5$.

stage appear in approximately the same number throughout the extent of the forming nucleus ambiguus. According to Ariëns Kappers ('12 and elsewhere), the ventrolateral migration of these cells is due to the neurobiotactic influences of cutaneous impulses distributed to the nucleus of the spinal root of the trigeminal nerve, near which the nucleus ambiguus takes its position. Not only are the migrating cells and those already in the position of the developing nucleus ambiguus of the multipolar type but there is an increase in the number of multi- 
polar cells within the common ${ }^{3}$ visceral efferent column. Neuraxes of these migrating special visceral efferent cell bodies, and of those already in position within the developing nucleus ambiguus, extend dorsomedially, along the path taken by the cell body in its course from its primitive position toward the common visceral efferent cell column, then they turn laterally and, joining with the neuraxes from cells within this column, continue laterally, ventral to the nucleus of the fasciculus solitarius and through the nucleus of the spinal root of the trigeminal nerve, to emerge from the lateral surface of the brain stem. At the same period that the special visceral efferent cell column is differentiating within the central nervous system, at the periphery individual masses of mesoderm appear as forerunners of various muscles supplied by this column.

The cells of the accessory cell column in the cervical cord all appear to be multipolar. Fibers turning into the afferent area of the spinal cord from among the emerging spinal accessory roots are found again at this age, although they are not so prominent as in the previous stage (see p. 110). Likewise scattered ganglia are found among the fibers of the spinal accessory nerve as it courses ventrolateral to the medulla oblongata, and the relationship between this nerve and the first dorsal root ganglion is the same as that discussed for the preceding stage.

The peripheral branches of the vago-accessory complex all show an increased development. Particularly those branches to the heart and lungs, originating from the nerve trunk as it courses caudad, lateral to the oesophagus, are better developed than in the earlier stages. The combined branch from the right and left vagi that swings dorsally at the cardiac end of the stomach (see p. 112) extends well caudad at this age and is joined by several fine branches from the coeliac ganglion. Fascicles from the sympathetic trunk are approaching the area of distribution of the vagus nerve about the oesophagus and the trachea. From the superior cervical ganglion one branch can be traced into close association with the superior laryngeal nerve, rostral to the nodose ganglion.

In the 15-day, 6-hour embryo. At this age there is the beginning of a longitudinal differentiation of the common visceral efferent cell column. A constriction is found between the cells of origin of the vagus nerve and those of the glossopharyngeal nerve, thus indicating the beginning of a separation of the column into a dorsal efferent nucleus

\footnotetext{
'The term 'common' is still used for this cell column during this and the following stage inasmuch as there probably are some of the special visceral efferent cells that have not as yet migrated from it. In the 16-day, 6-hour embryo, and the stages following, it is referred to as the 'general' visceral efferent column.
} 

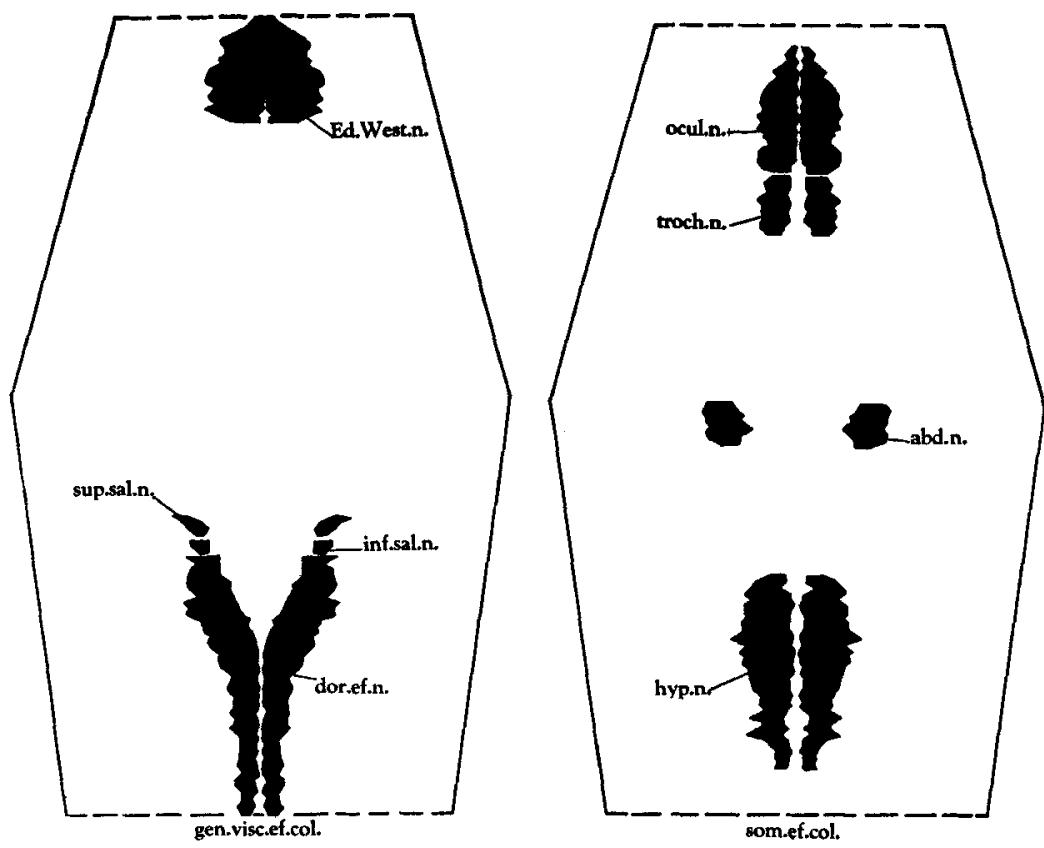

20

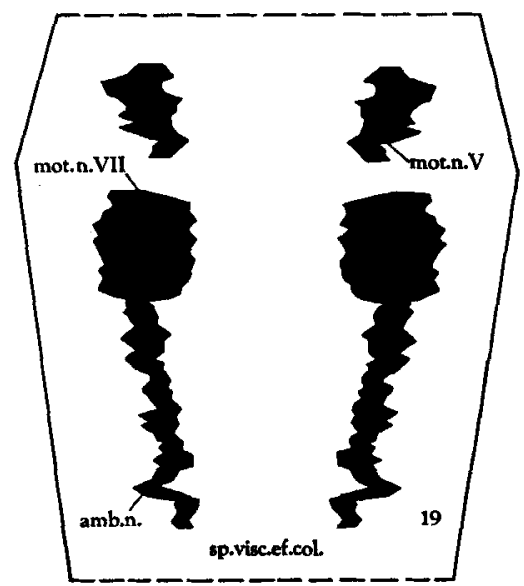

Figs. 18 to 20 Reconstructions of the somatie efferent, general visceral efferent and special visceral efferent columns of the adult rabbit brain. The legends are self explanatory. $\times 10$. 
of the vagus and bulbar accessory nerves and an inferior salivatory nucleus of the glossopharyngeal nerve. The special viseeral efferent column is more nearly developed than in the previous stage, although migrating cells are still found dorsomedial to it. This cell column is now characterized by a light staining, embryonic neuroglia.

Peripherally there is an increased distribution from the region of the oesophageal plexus toward the region of the heart and lungs, and the terminal branches from the cardiac end of the stomach extend through the coeliac plexus. In this plexus they join the thoracicolumbar sympatheties, to distribute with them to the pancreas and pass also to the region of the superior mesenteric plexus. In the distribution on the stomach wall the left vagus sends a branch dorsorostrally, which is distributed to the fundus while the caudally directed branches course past the pyloric end on to the walls of the primitive duodenum. Branches from the superior cervical ganglion are again traceable to the nodose ganglion and several branches from the former ganglion have invaded the pharyngeal plexus.

Fig. 21 A frontal section through the brain stem of a 13-day, 2-hour rabbit embryo dorsal to the internal genu of the facial nerve. It shows the relations of the motor trigeminal nucleus and the migrating special visceral efferent cells of the facial nerve. Note the most rostral part of the fasciculus solitarius and its nucleus; also the fiber connections between this nucleus and the migrating facial cells. Pyridine silver. $\times 28.8$.

Fig. 22 A sagittal section of a 13-day, 2-hour rabbit embryo indicating the area from which figure $22 a$ is taken. Pyridine silver. $\times 4.25$.

Fig. 22a A sagittal section through the rabbit brain from the area indicated in figure 22. Note particularly the migrating special visceral efferent cells of the facial nerve, both rostral and caudal to the cells of origin of the abducens nerve; also the abducens nucleus, and the most lateral of the trigeminal efferent cells. Attention is called to the rostrocaudal continuity of the various nuclear groups. Pyridine silver. $\times 38.5$.

Fig. 23 These cells are drawn with a camera lucida to show the relations of proprioceptive fibers to them. They are from the rostral group of the migrating special visceral efferent cells of the facial nucleus. ' $r$ ' illustrates fibers which appear to originate in the nucleus of the mesencephalic root of $V$, synapsing about these cells; ' $s$ ' shows a similar synapse of fibers having their origin in the geniculate ganglion. Pyridine silver. $\times 725$.

Fig. 24 A sagittal section through the brain stem of a 14-day, 6-hour rabbit embryo showing the continuity of the caudal cells of the motor nucleus of the trigeminal nerve with the rostral group of special visceral efferent cells of the facial nerve. Particular attention is called to the rostrally turning fibers of the sensory root of the glossopharyngeal nerve, and to the mesencephalic root of the trigeminal nerve continuing caudad to the level of the emerging facial root. Pyridine silver. $\times 26.5$. 

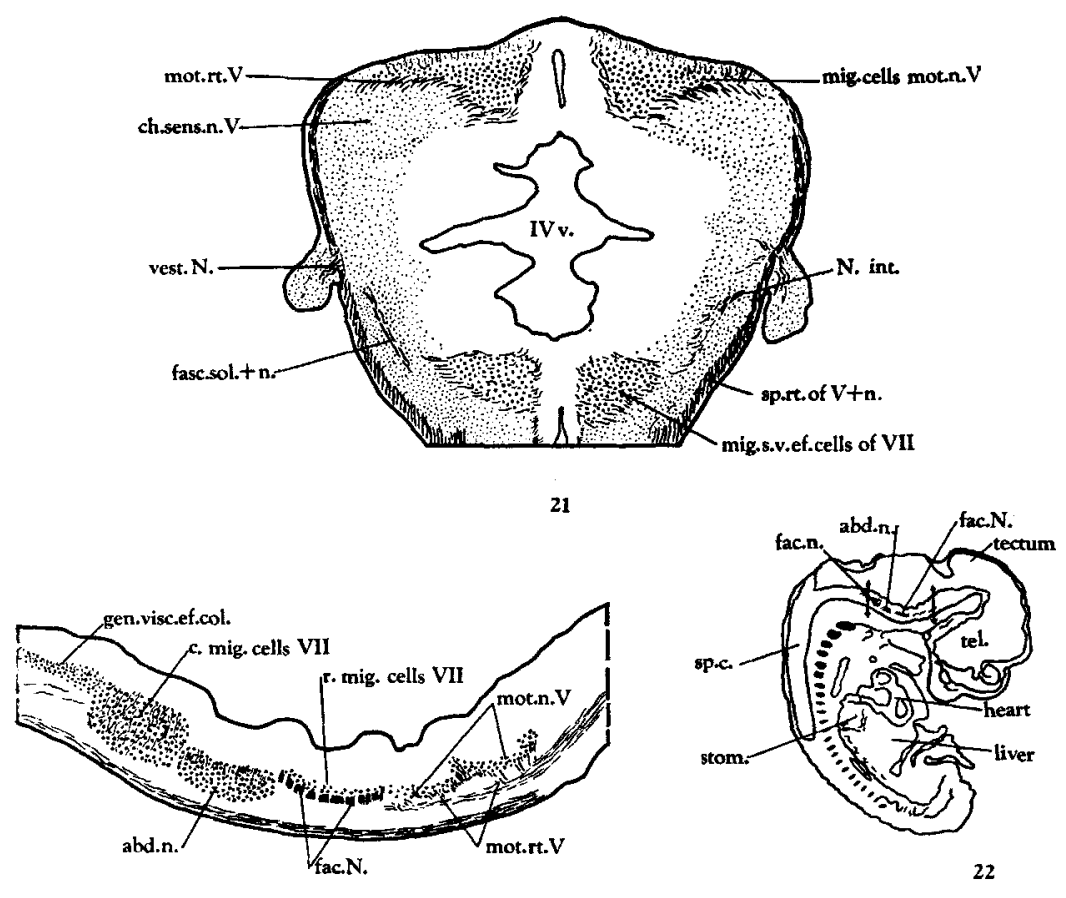

$22 a$
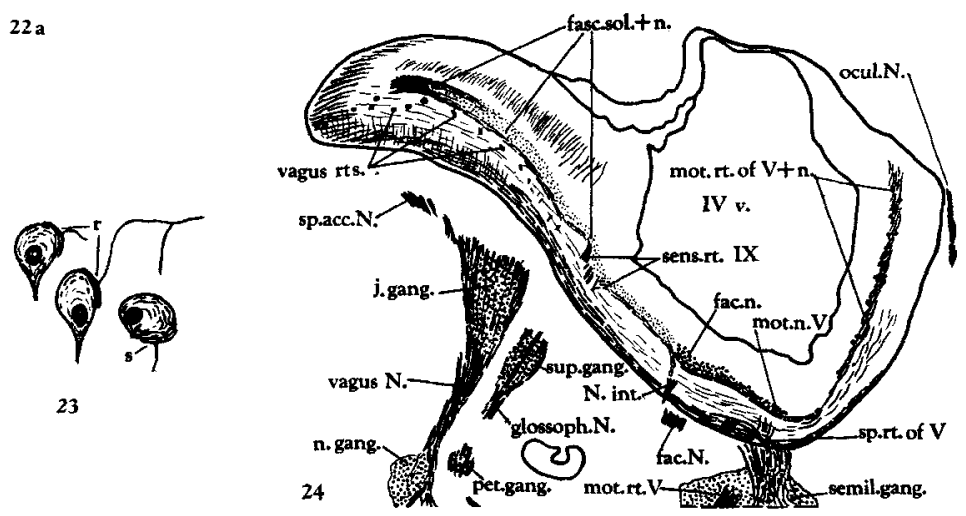

Figures 21 to 24 
In the 16-day, 6-hour embryo. The majority of the neurons of the general visceral efferent column are multipolar and two types of cells are distinguishable within it: a small type, which is uniformly scattered throughout the column; and a medium-sized cell, which is confined to the caudal two-thirds of the differentiating dorsal efferent portion of the column. Malone ('13) stated that the intermediate-type cells within the dorsal efferent nucleus of man (found between the main mass of the dorsal efferent nucleus and the hypoglossal nucleus) are cells of origin for preganglionic fibers carrying inhibitory impulses to the heart and so constitute a cardiac center. In the rabbit, at this age, the intermediate-type cells are scattered among the smaller cells of the nucleus and are found to the caudalmost extent of the column. Other observers who have located a cardiac center within the dorsal efferent nucleus are Molhant ('10), Wainstein ('21), and von Husten ('24). Ariëns Kappers, Huber and Crosby ('36) believe that probably preganglionic fibers to the heart originate in this nucleus since it gives rise to other preganglionic components of the vagus nerve. Kosaka ('09) placed the cardiac center of the dog medulla within the ventralmost neurons of the caudal portion of the nucleus ambiguus.

The separation between the salivatory nuclei and the dorsal efferent nucleus is not complete by this stage although a constriction is again found between these two portions of the general visceral efferent column. The nucleus ambiguus is completely differentiated caudally although some few migratory cells are still observed dorsomedial to the nucleus in its rostral portion. The cells of its rostral end are compactly grouped but those of the more caudal regions are somewhat scattered. This nucleus extends from a level slightly caudad to the calamus scriptorius caudally, to the caudalmost cells of the facial nucleus rostrally. 'The nucleus ambiguus and the facial nucleus overlap each other, to some extent, in all the material studied.

In their peripheral distribution, the vagal branches show an increased differentiation over those of the previous age. The auricular branch, which now originates from the vago-accessory trunk instead of from the region of the jugular ganglion (see p. 112), combines with the auricular branch of the glossopharyngeal nerve with which it is distributed peripherally in close relationship with the posterior auricular branch of the facial. There is an increased relationship between the superior cervical and the nodose ganglia, and more branches from the superior cervical ganglion have invaded the region of the pharyngeal plexus. Superior and inferior cardiac branches are now differentiated, the superior originating from the oesophageal plexus just caudal to the origin of the inferior laryngeal, and the inferior arising from the oesophageal plexus farther caudad. Both the superior and 
the inferior cardiac branches are accompanied by thoracico-lumbar sympathetics which have invaded the oesophageal plexus. Sympathetic branches can also be traced into the plexuses about the trachea and the bronchi and into the lungs. Fine branches from the plexus formation on the anterior wall of the stomach are traceable toward the hilus of the liver, and numerous scattered ganglion cells are found in this plexus at the origin of these branches. Terminal branches from both vagi are traceable caudad along the branches of the coeliac artery, toward the coeliac ganglion. They are joined by thoracico-lumbar sympathetic fascicles from this ganglion as they continue into the pancreas and, farther caudad, through the superior mesenteric plexus, into the mesentery of the gut. However, no branches enter the developing muscular walls of the gut at this time.

In the 17-day embryo. The constriction between the dorsal efferent and the inferior salivatory nuclei is more marked here than in the previous stage but there is not a complete separation between the two cell groups. The caudal pole of the dorsal efferent nucleus is now completely separated from the more caudally located cell columns of the spinal cord, and the special visceral efferent column is formed at all levels although the scattered arrangement of its cells is still evident in the more caudal portion.

In this and the following stages the peripheral distribution is the same as that deseribed for the 16-day, 6-hour embryo, with greater growth and greater distribution of the terminal branches within the walls of the structures which they have already invaded.

In the 20-day embryo. The inferior salivatory and the dorsal efferent nuclei are still not completely separated (fig. 5d). The rostral portion of the dorsal efferent nucleus and the more rostral cell groups of the general visceral efferent nuclear column, i.e., the inferior and superior salivatory nuclei, are located farther ventrolaterally in the brain stem than is the caudal portion of this column. The ventral turn of this nuclear column is due partially to the increase in the size of the nucleus intercalatus (or nucleus of Staderini) located just dorsomedial to this column.

In the 25-day embryo. The separation of the inferior salivatory and the dorsal efferent nuclei has now become complete. The cells of the accessory column of the cervical cord have adult characteristics and the neuroglia of this cell column has lost its embryonic appearance.

In the 1-day-old rabbit. Part of the available material of this age shows a distinct separation between the inferior salivatory nucleus and the dorsal efferent nucleus. In other series of the same age these two cell groups are still continuous although nearly separated. The cell bodies of the special visceral efferent neurons have an adult appear- 

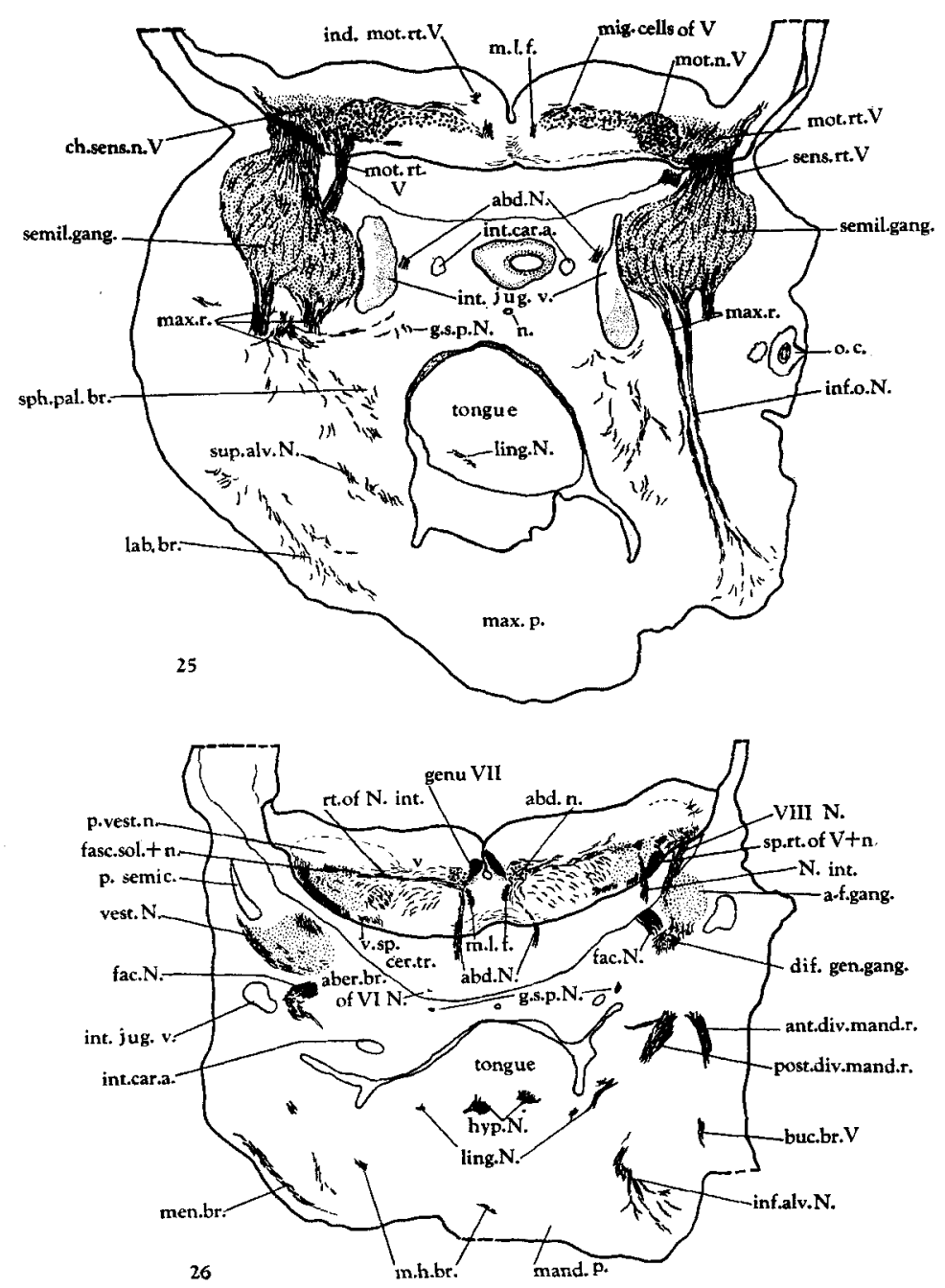

Fig. 25 A cross section through the brain stem of a 14-day, 6-hour rabbit embryo at the level of the emerging trigeminal nerve. Attention is called to the migration of the neurons of the motor nucleus of this nerve and to its indirect root fibers. Pyridine silver. $\times 26$.

Fig. 26 This figure is taken from the same embryo but at a more rostral level than that of figure 25. Note particularly the relation of the abducens nueleus, the direct root fibers of the nervus intermedius and the differentiating acoustico-facial ganglionic complex. Pyridine silver. $\times 22.5$. 
ance and the neuroglia both of this cell column and of the general visceral efferent column has lost its embryonic character.

In the 6-day-old rabbit. By this stage the cells of the general visceral efferent column have assumed an adult character.

The dorsal efferent nucleus in the adult rabbit. The dorsal efferent nucleus of the adult rabbit brain is composed of two distinct types of cells. The first (fig. $31 \mathrm{y}$ ) is a small, distinctly outlined neuron quite darkly stained in the toluidin blue preparation and having a very large nucleus with usually two or three nucleoli. Such cells are found throughout the length of the dorsal efferent nucleus although varying somewhat in position within this nucleus. The second type (fig. $31 \mathrm{z}$ ) is a larger cell (although smaller than those in the nucleus ambiguus), less deeply stained in the cell material and showing a massing of its granules. The nuclei of these latter cells do not appear so large in comparison to those of the smaller-type cell. This larger cell is confined to the caudal portion of the dorsal efferent nucleus. Slightly farther rostrally, at levels in which the hypoglossal and dorsal efferent nuclei are separated by the nucleus intercalatus, the larger cells of the dorsal efferent nucleus are more abundant in the ventrolateral area. Very few of these larger cells are found behind the caudal limit of the hypoglossal nucleus. These neurons, grouped thus in the ventral area of the dorsal efferent nucleus, are possibly homologous to the cells designated by Malone ('13) as the cardiac center in the dog. Other groupings of the cells within the dorsal efferent nucleus of the adult rabbit are noticeable although the divisions are not so distinct as those of the hypoglossal nucleus. At some levels groups similar to those designated as ventromedial, ventrolateral, and dorsolateral by Sanders ('29) for the sparrow are faintly evident. In reconstruction (fig. 18) the dorsal efferent nucleus presents a fairly irregular outline and shows an increase in the mediolateral diameter in its rostral half. The reconstruction also indicates the lateral turn of the rostral portion of the column. The dorsal efferent nucleus is in close relationship with the nucleus of the fasciculus solitarius, which is located lateral to it throughout the length of this efferent gray column. In the caudal region of the medulla oblongata it is bordered dorsally by the nucleus of the commissura infima, ventrally by the hypoglossal nucleus, and medially by the elosed portion of the fourth ventricle. Farther rostrally the dorsal efferent nucleus lies under the floor of the open fourth ventricle and is bordered dorsomedially by the nucleus intercalatus. Its rostrocaudal extent is $6.75 \mathrm{~mm}$.

The nucleus ambiguus in the adult rabbit. The nucleus ambiguus is located ventrolaterally (fig. 15) in the medulla oblongata, just medial to the nucleus of the spinal root of the trigeminal nerve and 
dorsolateral to the inferior olive. Its cells, which are large, multipolar elements with a fairly uniformly distributed granular substance and large, light staining nuclei, show a relatively compact arrangement except in the caudal end of the nucleus (see p. 118). On reconstruction (fig. 19), the nuclear column is seen to be quite saw-toothed in outline, particularly caudally, due to the scattered arrangement of the constituent neurons. Rostrally this column is somewhat increased in diameter and overlaps the facial nucleus. The length of this nucleus is $6.3 \mathrm{~mm}$.

The accessory cell column in the adult rabbit. The cells forming this column, as studied in the upper segments of the cervical cord, resemble in every respect those of the nucleus ambiguus. The column is located lateral to the central canal and is confined to the upper seven segments of the cervical cord. The similarity between the cells of this column and those of the nucleus ambiguus and the lateral position of these cells suggest that they are of the special visceral efferent type. At no stage in development, after the various efferent columns begin to be differentiated, does the spinal accessory nuclear column appear to be continuous with any of the efferent columns of the brain stem.

Fig. 27 A cross section illustrating, in a 14-day, 21-hour rabbit embryo, the relationship of the caudal cells of the trigeminal motor nucleus and the emerging facial nerve. Note also the indirect root fibers from these caudal cells of the motor trigeminal nucleus coursing medially. Pyridine silver. $\times 22.5$.

Fig. 28 A cross section of the brain stem of a 13-day, 21-hour rabbit embryo showing the relationship between the most rostral cells of the general visceral efferent column and the ventrolaterally migrating cells of the facial nerve. The emerging abducens nerve and the relationship between the nucleus of the fasciculus solitarius and the migrating cells of the facial are also illustrated. Pyridine silver. $\times 26$.

Fig. 29 Key drawing through the brain stem of a 20-day rabbit embryo to show the area from which figure $29 a$ is taken. Pyridine silver. $\times 2.5$.

Fig. 29a A sagittal section through the area designated in figure 29, to show the continuity between the gray of the accessory abducens nucleus and of the motor nucleus of the trigeminal. Note also the relations of the emerging facial nerve and the ventral facial nueleus. Pyridine silver. $\times 29$.

Fig. 30 Key drawing to show the area from which figure $30 a$ is taken. This figure is a sagittal plane through a 20 -day rabbit embryo. Pyridine silver. $\times 4.5$.

Frig. 30a This figure illustrates the area designated in figure 30 and is drawn to emphasize the course of the indirect root fibers of the trigeminal nerve. Note the positions of the mesencephalic root of the trigeminal nerve, the facial nerve, and the primordial vestibular nucleus. Pyridine silver. $\times 26$.

Fig. 31 Camera lucida drawing of cells from the general visceral efferent column. ' $w$ ' and ' $x$ ' are cells from the superior salivatory nucleus and ' $y$ ' and ' $z$ ' are from the caudal portion of the dorsal efferent nucleus. Pyridine silver. $\times 515$. 


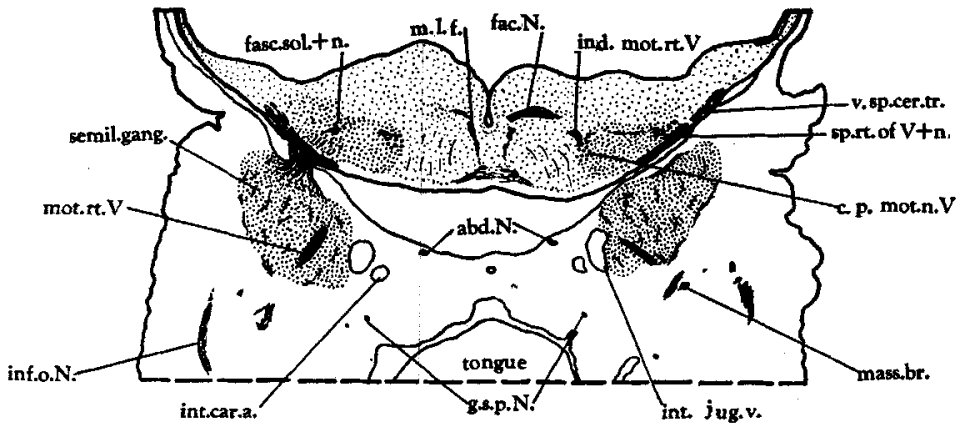

27
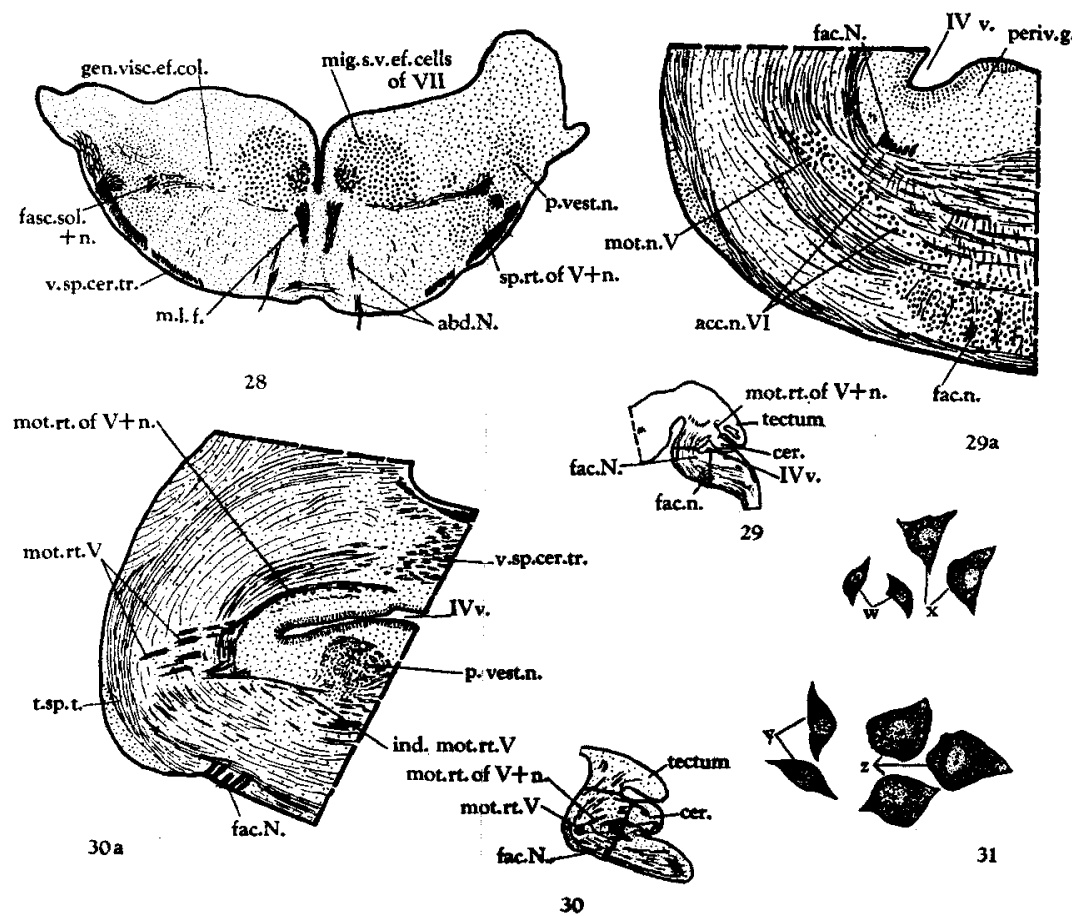

mot.rt.of V+n. fac.n. IVv.
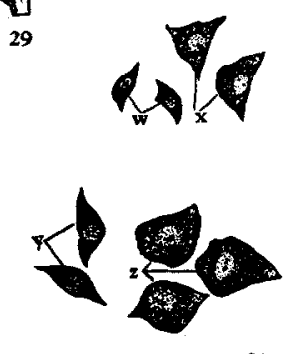

31

Figures 27 to 31 
That it is sometimes continuous with the dorsal efferent group of cells in mammals has been shown by Ariëns Kappers (Ariëns Kappers, Huber and Crosby, '36) in his work with the sheep embryo. The fusion of the spinal accessory cell column rostrally with the nucleus ambiguus (as occurs at times) is regarded by Vermeulen ('18) as a secondary condition due to the caudal lengthening of the nucleus ambiguus. Addens ('33) regarded the spinal accessory nerve of mammals as somatic efferent and Beccari ('13, '22) identified a distinct spinal accessory nucleus in the sparrow, in line with the somatic efferent column of the spinal cord as represented in the dorsal hypoglossal nucleus.

\section{The glossopharyngeal}

In the 11-day embryo. The glossopharyngeal nerve originates from both the common efferent cell column of the brain stem and the primitive ganglia of the nerve root. The cells of the common efferent column contributing to the glossopharyngeal nerve are confined to a single neuromere ( $\mathbf{E}$ of fig. 1a), just rostral to that giving rise to the vagus nerve. This common efferent cell column, which is continuous throughout the brain stem and into the spinal cord (fig. 1a), is discussed in detail in conjunction with the hypoglossal nerve (see p. 86). Neuraxes from the bipolar, oval cells of origin located laterally within this cell column run dorsolaterally in several strong fascicles to emerge from the lateral surface of the brain stem in close relationship with the entering, centrally directed processes of the primitive ganglion cells located on the glossopharyngeal root. Immediately upon emergence, the bundles form a rather loosely arranged trunk and turn ventrally through the undifferentiated mesenchyme (fig. 2) to distribute as far caudally as the pharynx. Lateral to the developing pharynx, the root branches into numerous, fine, and slightly knobbed endings. Scattered along the root, almost to its termination, are the primitive ganglion cells (fig. 2).

In the 12-day embryo. The common visceral efferent cell column is composed of more, and slightly larger cells than earlier, with increased neurofibrillar material near their peripheries. The superior and petrous ganglia are differentiated, as is the branch to the tympanic plexus, which arises from the nerve at the level of the petrous ganglion to distribute ventrally for a short distance within the immediately surrounding mesenchyme. The nerve terminates in a ventral branch which is the precursor of the lingual nerve and a more dorsal branch which is a direct continuance of the glossopharyngeal nerve and is the forerunner of the pharyngeal nerve (fig. 3 ).

In the 13-day, 2-hour embryo. The common viscersal efferent cell column is differentiated (fig. 8) and extends caudally from a level 
slightly behind the developing abducens nucleus to become continuous with a similarly located column in the spinal cord (see pp. 107 and 130). Due to the continuity of this gray, that portion of the column contributing to the glossopharyngeal nerve can be determined only by tracing the roots of this nerve centrally. Accompanying these roots as they course dorsolaterally through the brain stem ventral to the nucleus of the fasciculus solitarius are fine fascicles which continue medially to be distributed to the nucleus praepositus and the nucleus intercalatus.

The cells of the common visceral efferent column are still of the bipolar type, but show greater development of processes than do those of the 12-day embryo. This cell column is now characterized by the light staining, embryonic neuroglia.

Peripherally (fig. 4), the tympanic branch is distributed ventrally through the mesenchyme ventromedial to the petrous ganglion. The lingual branch extends well into the dorsal part of the second branchial arch and has ganglion cells scattered along its course. A fine filament from the sympathetic (thoracico-lumbar) plexus on the lingual artery joins this branch near its termination. The pharyngeal branch extends slightly farther caudad and breaks up into several fine terminations just rostral to the ending of the pharyngeal branches of the vagus nerve lateral to the developing pharynx.

In the 14-day, 6-hour embryo. A few of the cells of the common visceral efferent column are multipolar at this stage. This column is somewhat ventrolateral in the medulla oblongata at the level at which it gives rise to the glossopharyngeal nerve. The column is still continuous rostrally with the cells of origin of the facial nerve and caudally with those giving rise to the vagus nerve.

Peripherally two auricular branches of the glossopharyngeal nerve, which arise from the nerve root at the level of the superior ganglion and distribute laterally into the mesenchyme, join the auricular branch of the vagus nerve just beyond the ganglion. The tympanic branch, as it courses toward the region of the tympanic plexus, is closely paralleled by branches of the carotid plexus from the superior cervical ganglion. The lingual branch is distributed within the dorsal part of the developing tongue and has the same relations with the plexus about the lingual artery as were observed for the previous series. The pharyngeal branches of the glossopharyngeal and vagus nerves are now in plexus formation about the walls of the pharynx and sympathetic fibers from the superior cervical ganglion are approaching this region.

In the 14-day, 21-hour embryo. The special visceral efferent column has begun to develop (fig. 10). In the caudalmost portion of the brain 
stem many cells of this column are already in position, with scattered neurons in all stages of migration between this ultimate position and the common visceral efferent column. At the level of origin of the glossopharyngeal nerve very few cells have reached their final position but many are found in the migratory stages. The migrating cells are all of a slightly larger type than those remaining in the common visceral efferent column and are multipolar. The neurobiotactic influences resulting in this migration are discussed in detail in conjunction with the vagus nerve (see p. 113). More of the cells in the common visceral efferent column show multipolarity at this stage than did those in the 13-day, 2-hour embryo. The migrating special visceral efferent cell bodies of the facial nerve are quite proximate to the medial aspect of the rostral portion of the common visceral efferent column. Some of these cells are quite closely associated with the cells of origin for the glossopharyngeal and facial nerves which are located in the common visceral efferent column at this time. The two types of cells can be readily distinguished, however, since the migrating cells are larger and present a greater number of processes than do the others. Within the rostral portion of the common visceral efferent column the cells of origin of the preganglionic components of the glossopharyngeal and facial nerves lie in intimate relationship with each other, with the cells of the facial component lying dorsomedial to-or sometimes intermingled with-those contributing to the glossopharyngeal nerve.

Peripherally, the branches of the glossopharyngeal nerve show an increased differentiation over those of the 14-day, 6-hour embryo. The auricular branch, with a similar branch from the vagus, has joined the posterior auricular branch of the facial nerve and is distributed with it toward the region of the external ear. A second auricular branch from the superior ganglion is distributed independently toward this area. The pharyngeal plexus shows an increased complexity and the sympathetic (thoracico-lumbar) fibers have extended nearer to it but do not as yet enter into its formation. Some of these fine branches from the superior cervical ganglion, however, are now connected with the petrous ganglion, and there is an increased relationship between this system and the lingual branch of the glossopharyngeal nerve on the dorsum of the developing tongue. The tympanic branch from the lateroinferior aspect of the petrous ganglion extends well toward the region of the otic ganglion and is approaching plexus formation with branches from the plexus about the internal carotid artery and a branch from the geniculate ganglion. An anastomotic branch, arising from the glossopharyngeal nerve just below the petrous ganglion, joins a branch of the facial nerve as it is distributed into the differentiating mesenchyme of the posterior belly of the digastric muscle. 
In the 15-day, 6-hour embryo. The special visceral efferent column is better developed than in the preceding stage (see p. 126). Also the beginning of a differentiation of the common visceral efferent cell column into the dorsal efferent and the inferior and superior salivatory nuclei is indicated by a slight constriction of the column between the cells giving rise to preganglionics of the vagus and those giving origin to the comparable fibers of the glossopharyngeal nerve.

The meningeal branch is found for the first time. It originates from the medial aspect of the nerve trunk just above the petrous ganglion and courses dorsomedially to be distributed to the meninges of the brain stem just rostral to the area of distribution of the meningeal branch of the vagus. Other branches are essentially the same as in the previous stage except that they show further development and increased relations with the sympathetic system, which has now invaded the pharyngeal plexus.

In the 16-day, 6-hour embryo. The differentiation of the dorsal efferent nucleus from the remainder of the general visceral efferent column is still incomplete. The preganglionic neurons of the facial and glossopharyngeal nerves intermingle as yet to some extent but are more segregated than in the previous stage. A few scattered migrating special visceral efferent cells are still found at the level of the glossopharyngeal nerve, just dorsomedial to the now fairly well developed nucleus ambiguus. The concomitant differentiation of the mesenchyme into muscle groups peripherally and the development of the special visceral efferent cell column centrally are worthy of reemphasis.

Peripherally, the tympanic branch has invaded the area of the tympanic plexus and is in plexus formation with the sympathetic branches from the internal carotid plexus and with a branch from the geniculate ganglion of the facial nerve. The tonsillar branch is distinguishable from the lingual portion of the nerve and is distributed laterally into the region about the root of the tongue. The pharyngeal plexus has increased in complexity and is invaded by several fine branches from the superior cervical ganglion; a few fine interconnecting branches are observed between this ganglion and the petrous ganglion.

In the 17-day embryo. At this stage the differentiation of the general visceral efferent cell column is more noticeable than in the 16-day, 6-hour embryo, the separation between the dorsal efferent and the inferior salivatory nuclei being practically complete. The cells of the superior salivatory nucleus no longer intermingle with the inferior salivatory neurons as has been the condition in the previous two stages but are now continuous rostrally in the column. The special visceral efferent cell column is completely formed throughout the extent of the 
nucleus ambiguus and is compactly arranged at the level of the glossopharyngeal nerve.

The branches of the glossopharyngeal which have invaded the various areas of distribution in the 16-day, 6-hour embryo show practically no further differentiation in this and the following stages. For this distribution the reader is referred to the previous two stages (p. 126).

In the 20-day embryo. The separation between the inferior salivatory and the dorsal efferent nuclei is not as yet complete (fig. 5d). The inferior salivatory nucleus is continuous rostrally with the superior salivatory nucleus of the facial nerve.

Peripherally the anastomotic branch between the glossopharyngeal nerve and the digastric branch of the facial nerve is persistent, and another anastomotic bundle from the petrous ganglion accompanies the chorda tympani as it courses ventromedially to join the lingual branch of the trigeminal nerve.

In the 25-day embryo. The dorsal efferent and inferior salivatory nuclei are completely separated and the differentiation between the inferior salivatory and superior salivatory nuclei is more apparent.

In the 1-day-old rabbit. As mentioned in the discussion of the vagoaccessory complex (p. 119), some of the older material used in this study does not show a complete separation between the dorsal efferent and the inferior salivatory nuclei. At this stage the neuroglia of both the general and the special visceral efferent cell columns has lost its embryonic characteristics and the cells of the nucleus ambiguus resemble adult neurons.

In the 6-day-old rabbit. The cells of the general visceral efferent column have assumed adult characteristics and the separation between the inferior and superior salivatory nuclei is practically complete. The cells of the rostral portion of this column appear quite scattered, particularly in the region of the superior salivatory nucleus, where they are located quite far ventral to the main group of cells.

The inferior salivatory nucleus in the adult rabbit. The cells of the inferior salivatory nucleus are of the same type as those of the dorsal efferent nucleus (p. 121 and fig. 31). They are compactly arranged and are quite closely related caudally with the dorsal efferent nucleus and rostrally with the superior salivatory nucleus although they are slightly separated from these structures (figs. 5d and 18). The inferior salivatory nucleus lies ventral to the medial vestibular nucleus and ventromedial to the lateral vestibular (Deiters') nucleus. On its lateral surface it is closely associated with the small-celled portion of the nucleus of the fasciculus solitarius. Dorsomedial to it, between it and the floor of the fourth ventricle, is the nucleus intercalatus. Wink- 
ler and Potter ('11, pl. XXXII) give the position of the inferior salivatory nucleus but they label the cell group dorsomedial to it " $a$ of the nucleus dorsalis Nervi VIII"' and do not indicate any group of cells at this level as the nucleus intercalatus. In the toluidin blue material used for this study the more medial of the cells dorsomedial to the inferior salivatory nucleus are part of the nucleus intercalatus and a fairly distinct break is found between this group and the medial vestibular nucleus. The inferior salivatory nucleus has a rostrocaudal extent of $0.45 \mathrm{~mm}$. and presents a fairly regular outline in reconstruction (fig. 18). For discussion of the nucleus ambiguus see page 121.

\section{The facial}

In the 11-day embryo. At this stage the facial nerve appears to arise from a single neuromere (see below and $\mathrm{C}$ of fig. 1a), the second rostral to that giving origin to the glossopharyngeal nerve and the one adjacent rostrally to that giving origin to the abducens nerve. The cells of origin are located in the undifferentiated common efferent column (see discussion under the hypoglossal nerve, p. 86 and fig. 1a). Neuraxes from these cells gather into fine fascicles as they course ventrolaterally through the brain stem to emerge from the lateral surface of this structure. Such emerging fibers are accompanied by incoming afferent fibers, some of which turn down into the longitudinal bundle (which represents the undifferentiated spinal root of the trigeminal nerve and the fasciculus solitarius). From their superficial origin the roots turn ventrally and course through the rostral portion of the acoustico-facial ganglionic complex (fig. 2) to distribute within the mesenchyme of the second branchial arch. The nerve roots show indications of gathering into a single trunk as they pass through the ganglionic complex but begin to break up into fine terminal branches upon reaching the inferior aspect of this structure and are rather loosely arranged throughout the remainder of their course. The terminations are the finely divided, slightly knobbed endings characteristic of motor endings at such early developmental stages.

In the 12-day embryo. At this age the roots of the facial nerve have their superficial origin from the same neuromere ( $C$ of fig. 1a) as in the 11-day embryo but the cells of origin are found within two neuromeres: a rostral neuromere (which gives superficial origin to the nerve) and a second, immediately adjacent caudal neuromere (D of fig. 1a). The neurons are bipolar and are still undifferentiated from the common efferent cell column. The neuraxes of the cells of the more caudal neuromere at first course somewhat medially ; then, gathering into a fairly large band, they turn rostrally and extend forward, 
within the brain stem, as the earliest indication of the internal genu of this nerve.

From their superficial origin on the lateral surface of the brain stem, the nerve roots turn ventrally and collect into a fairly compact nerve trunk which runs caudally and somewhat dorsally through the rostral portion of the acoustic-facial ganglionic complex. From the inferior boundary of this structure the nerve continues caudalward and, at the same time, somewhat dorsolaterally into the second branchial arch, to terminate in the primordial temporo-facial and cervico-facial divisions. The rostroventral portion of the acousticofacial ganglionic complex shows the beginning of a differentiation of the geniculate ganglion. The greater superficial petrosal nerve arises from this differentiating ganglion and courses ventrolaterally toward the region of the as yet undeveloped sphenopalatine ganglion. The chorda tympani branch, arising from the nerve trunk caudal to the ganglion but before the fibers enter the second branchial arch, extends medioventrally, and then rostromedially through the dorsal part of the second arch into the mandibular portion of the first arch, in which region it ends just dorsal to the mandibular ramus of the trigeminal nerve. An anastomotic branch from the geniculate cells enters the petrous ganglion of the glossopharyngeal nerve.

In the 13-day, 2-hour embryo. The viseeral efferent column is differentiated from the somatic efferent column, but the cells of origin of the facial nerve are still continuous caudally with the cells of origin of the glossopharyngeal nerve and rostrally with the cells giving rise to the motor root of the trigeminal nerve. Just caudal to the differentiating abducens nucleus, the efferent neurons of the facial nerve have a dorsoventral extent several times that of the area occupied by the neurons contributing to the glossopharyngeal nerve. Slightly farther rostralward, medial to the abducens group, the facial column becomes constricted. It spreads out again, although to a lesser extent, just rostral to the abducens nucleus. The continuity of the efferent column at this level is due to the migration of the more rostral cells contributing to the facial nerve through the region of the developing genu. Cells supplying the facial nerve are found in all stages of migration. Among them, particularly in the ventrolateral portion of the forming genu, are small, bipolar, receptive neurons which intermingle with the medial cells of the abducens nucleus and are continuous caudally with the central cells of reception of the glossopharyngeal and vagus nerves located about the hypoglossal nucleus (see p. 125). At this stage, as well as in the following one, buton-like synapses are found about the more rostral efferent cells of the facial nerve (fig. 23). The fibers forming these synapses originate more rostrally in the brain 
stem. Longitudinal bundles (identical in appearance with those of the mesencephalic root which emerge with the trigeminal motor nerve) continue caudad to the level of the emergent facial nerve and then apparently bifurcate. They either terminate as fine branches around the cells of origin of the facial nerve or continue out of the brain stem with its motor root. Other fibers appear to enter with the emerging motor root and to end about the efferent cells of this nerve in a similar manner.

Neuraxes from the more caudally located cells of the facial nerve course rostrally among the cells in the migratory phase and medial to the abducens nucleus. At the level of the rostral limit of the abducens nucleus they turn ventrolaterally and join the neuraxes from the rostrally located facial neurons, with which they emerge from the lateral surface of the brain stem in five or six fairly strong roots. From their superficial origin they turn ventrocaudally and then collect into a single trunk as they pass through the rostroventral portion of the now fairly well differentiated acoustic-facial ganglionic complex. As the nerve trunk courses through the differentiating geniculate ganglion, it gives origin to the greater superficial petrosal nerve which ends in close relationship with the sphenopalatine branches of the maxillary ramus of the trigeminal nerve in the region of the still undifferentiated sphenopalatine ganglion. The main trunk continues caudally and dorsolaterally from the lower boundary of the geniculate ganglion and enters the second branchial arch. Just below the ganglion it gives rise to a fine branch which is distributed dorsally into the region of the future stapedius muscle. The chorda tympani fibers distribute ventromedially into the first branchial arch, in which region they join the now differentiated lingual branch of the mandibular ramus of the trigeminal nerve. The temporo-facial division is distributed ventrally and quite superficially about the posterior portion of the lower jaw and the cervico-facial division extends into the region of the undifferentiated platysma muscle.

In the 14-day, 6-hour embryo. The efferent cells of the facial nerve are differentiated into two distinct groups. Those of the rostral end of the common visceral efferent column contributing to this nerve, although still continuous in the column, are separated from, and lie lateral to, the more caudal of the ventrolaterally migrating special visceral efferent cells. More of the primitively more rostrally located neurons of the medial cell group have migrated caudally through the genu region, and the larger, multipolar neurons of this group, located about the caudal part of the forming genu, are shifting ventrolaterally toward the position of the facial nucleus in the adult rabbit. The small-celled component of this medial cell group is still found among 
the fibers of the genu and along the medial boundary of the abducens nucleus (see pp. 103 and 135).

Numerous cells rostral to the genu contribute to the facial root. These are mostly multipolar and have apparently shifted ventrolaterally, without traversing the region of the genu (fig. $22 \mathrm{a}$ ). A few fine fibers turn out of the emergent root and synapse in pericellular fashion about these cells (fig. $23 \mathrm{~s}$ ). This suggests that cell bodies of the proprioceptive neurons may lie in the geniculate ganglion, their neuraxes entering the brain stem among the fibers of the emergent motor root as Wakeley and Edgeworth ('33, see p. 130) believed. The fibers which appear to arise from the mesencephalic nucleus of the trigeminal and synapse about these cells, or emerge with the motor root (see p. 131), are again quite evident.

The acoustic-facial ganglionic complex shows further differentiation but the more dorsally located cells of the geniculate ganglion are still closely related to the differentiating vestibular ganglion. The greater superficial petrosal nerve receives some contributions from the geniculate ganglion. In the region of the sphenopalatine ganglion, as this nerve is distributed with palatine branches from the maxillary division of the trigeminal, a few scattered sympathetic ganglion cells are present, indicating the beginning of the ganglion. The chorda tympani nerve, in conjunction with the lingual branch of the trigeminal, extends into the developing tongue bud, and an anastomotic branch from the petrous ganglion now joins the differentiated branch of the facial nerve to the digastric muscle (see p. 126). Auricular branches of the vagus and glossopharyngeal are in close association with the posterior auricular nerve as it courses toward the occipital region.

The two terminal divisions of the facial nerve show a greater distribution within the superficial mesenchyme of the face at this age than in the 13-day, 2-hour embryo. They end in close relationship with terminal branches of the trigeminal nerve, but as yet no anastomoses are evident.

In the 14-day, 21-hour embryo. The rostral portion of the common efferent cell column, which is located somewhat farther ventrolateral than the caudal portion of the column, is better differentiated than in the previous stage. It is still closely associated on its lateral aspect with the nucleus of the fasciculus solitarius and contains some multipolar neurons. The rostralmost cells contributing to the preganglionic component of the facial nerve are found at a level just caudad to the entering nervus intermedius; caudally this cell group is continuous with the cells of origin of the glossopharyngeal nerve, the neurons of the two groups intermingling to some extent. The larger cells (the primitive special visceral efferent cells) of the 
medial cell group have, for the most part, shifted caudally along the developing genu and the ventrolateral migration of the older, multipolar cells has progressed so that many are now in the adult position of the facial nucleus. Ventrolateral migration of facial neurons rostral to the abducens nucleus is still evident, many cells being found among the emergent root fibers, again suggesting that the motor facial nucleus is ultimately composed of neurons which have migrated directly ventrolaterally, anterior to the abducens nucleus, and others (greatly in the majority) which have migrated caudally, thus producing the genu, before beginning to shift ventrolaterally. Since the ventrolateral migration of the special visceral efferent cells of the facial nerve is due mostly to the influence of the sensory nuclei of the trigeminal nerve, the difference in path of migration may be explained as follows. Those cells which give rise to neuraxes supplying muscles underlying areas innervated by the maxillo-mandibular portion of the trigeminal nerve are influenced mostly by the sensory cells of reception for this portion of the trigeminal nerve. This is the most rostral portion of the nucleus of the spinal root and the chief sensory nucleus of the trigeminal. Thus, the migration, following the path of least resistance, proceeds frontal to the cells composing the abducens nucleus. Likewise, cells of the facial nucleus supplying neuraxes to muscles underlying areas innervated by the ophthalmic division of the trigeminal nerve are influenced by the nucleus of the spinal root of this nerve since the cells of reception for the ophthalmic division are located therein. The caudal migration must precede the ventrolateral migration since, due to their position, the cells of origin of the abducens nerve block off a direet ventrolateral shift. Yagita ('10) has shown that the temporal branches of the facial nerve arise from the entire dorsal part of the facial nucleus in the rabbit.

Secondary fibers originating from the cells of the fasciculus solitarius are accompanied medially by direct root fibers of the nervus intermedius. Some of these end in the general visceral efferent column at this level and others continue centrally to terminate about the small-celled clusters of the primitive medial cell group or to lose themselves within the fibers of the genu (fig. 26). These latter are probably coursing caudad in this structure and then turn ventrolaterally to end about the cells already in the adult position of the facial nucleus.

The peripheral distribution of branches of the facial nerve is the same at this age as for the 14-day, 6-hour embryo except that they show greater development. Medial to the greater superficial petrosal nerve (which arises at the level of the now completely differentiated geniculate ganglion), as it courses toward the sphenopalatine gang- 
lion, is a large branch from the superior cervical ganglion. This branch extends into the region of the sphenopalatine ganglion (which also shows further development) independently of the greater superficial petrosal nerve. A second branch from the superior cervical ganglion joins the main trunk of the facial nerve just rostral to the origin of the chorda tympani. The terminal branches of the facial nerve show several anastomoses with the terminal fibers of the trigeminal nerve in the region of the mandible and posterior to the eye. The posterior auricular branch, which has now incorporated the auricular branches of the vagus and glossopharyngeal nerves, is distributed in close positional relation with the cervical nerves in the occipital region and cervical branches are in close association with the spinal nerves in the region of the platysma muscle.

In the 15-day, 6-hour embryo. The cells of the common efferent column contributing to the facial nerve gather slightly rostralward to lie along, and somewhat among, the dorsomedial cells contributing to the glossopharyngeal root. A greater number of the special visceral efferent cells have now migrated from their primitive medial position to form a facial nucleus continuous with the developing nucleus ambiguus. The cells of the latter nuclear group slightly overlap the ventral facial nucleus. Both of these nuclear groups are characterized by light staining, embryonic neuroglia at this stage. Numerous special visceral efferent cells are still in the migratory stage between the genu and the developing ventral facial nucleus and others are gathered about the posterior aspect of the developing genu. The small, receptive cells of the primitive medial cell group are gathering into scattered groups about the mediocaudal aspect of the abducens nucleus and are continuous caudally with the nucleus praepositus (see p. 103).

The greater superficial petrosal nerve now joins with the branch from the superior cervical ganglion to enter the sphenopalatine ganglion as the nerve of the pterygoid canal (vidian nerve). The terminal branches of the facial are distributed more widely about the region of the eye and of the lower jaw. More anastomoses between these branches and the terminal branches of the trigeminal are found.

In the 16-day, 6-hour embryo. The cells of the general visceral efferent column contributing to the facial nerve all appear multipolar. The majority of the special visceral efferent cells have reached the position of the ventral facial nucleus and only a few scattered, migrating cells are found about the caudal portion of the internal genu. All of these cells appear to be multipolar. The only difference in peripheral distribution is an inereased relation between the terminal branches of the facial and of the trigeminal nerves in the temporal region. 
In the 17-day embryo. The ventral facial nucleus is completely formed and the beginning of its differentiation into subgroups is evident. This differentiation has not yet progressed sufficiently to permit the distinguishing of the various groups described by van Gehuchten (1899 and '03), Yagita ('10), Papez ('27) and others in their studies of the localization pattern within the nucleus for specific muscles supplied by this nerve. The peripheral distribution of the facial nerve is the same at this age as in the 15- and 16-day embryos.

In the 20-day embryo. A constriction now indicates the differentiation of the rostral end of the general visceral efferent column into the superior and the inferior salivatory nuclei. The facial nucleus shows further indications of cell grouping. The small receptive neurons of the more primitive central gray mass no longer lie among the fibers of the genu but are ventrolateral to this structure along the ventromedial border of the abducens nucleus. These neurons form an interrupted column which is continuous with the cells contiguous to the hypoglossal nucleus (see p. 101). The accessory abducens nucleus, which is in formation at this age, is located dorsomedial to the rostral portion of the ventral facial nucleus, and, in the available material, neuraxes from this gray cannot be traced into the emergent facial root (see p. 101).

In peripheral distribution the facial nerve has spread farther toward the temporal region and further anastomoses between its terminal branches and those of the cutaneous portion of the lachrymal and zygomatico-temporal divisions of the trigeminal nerve are found.

In the 22-day embryo. There is an increased differentiation, but not a complete separation, between the superior and inferior salivatory nuclei, and the division of the ventral facial nucleus into cell groups is apparently completed. The divisions of this nucleus are discussed in detail on page 137.

In the 25-day embryo. The only noticeable difference at this age is the increase in size of the cells of the ventral facial nucleus. These neurons also show more processes than do the comparable cells of the 22-day embryo.

In the 1-day-old rabbit. The cells of the ventral facial nucleus have assumed all of the characteristics of adult neurons. They possess more processes and are larger than in any of the previous stages. The neuroglia of this nucleus, as well as that of the nucleus ambiguus, has lost its embryonic charaeter.

In the 6-day-old rabbit. The inferior and superior salivatory nuelei are not yet entirely separated. Their cells, which are smaller than those of the special visceral efferent column, have assumed adult characteristics. In these older stages, and in the adult rabbit, the 
emerging facial root courses ventrolateralward through the brain stem at such a level that its most caudal fascicles pass just dorsal to the rostral part of the ventral facial nucleus. In the younger embryos this root emerges at a level anterior to the rostral limit of the nucleus. This change in relations is probably due to the increased size of the nucleus and also to a caudal shift of the emerging root due to the development of the pons. This, and the rostral direction taken by the abducens fibers (see p. 100), results in the emergence of the facial and abducens roots at practically the same level in the adult (see Ariëns Kappers, Huber and Crosby, '36, fig. 294H, p. 595).

Crossing root fibers of the facial efferent component are not found in any of the available material. Addens ('34) was of the opinion that there are crossed fibers of the efferent facial root and believed, with others, that they are secretory for salivary glands. Kohnstamm ('02) located this crossed component experimentally in the dog, as did Kaida ('29) in the rabbit. These investigators placed the cells of origin for the crossed component dorsal to the ventral facial nucleus.

The superior salivatory nucleus in the adult rabbit. This nucleus is composed of two types of cells, both of which are small, preganglionic neurons. For comparison and description these two kinds of neurons are spoken of as type $a$ and type $b$. The type $a$ cells of this nucleus are identical in size, in shape, and in staining characteristics with the cells described for the inferior salivatory nucleus (see p. 128 and fig. $31 \mathrm{x}$ ). They are more abundant in the caudal portion of the nucleus, in which region they intermingle with the type $b$ cells. Rostrally they are more or less confined to the dorsomedial area of the nucleus. The type $b$ cells (fig. $31 \mathrm{w}$ ) are of the same character as the type $a$ neurons except that they are only about one-half as large and usually do not stain so deeply. In the rostral part of the nucleus they appear to be gathered toward the ventral and ventrolateral areas of the gray mass. The superior salivatory nucleus is located in the brain stem ventrolateral to the fourth ventricle and medial to the nucleus of the fasciculus solitarius. It is ventromedial to the nucleus intercalatus and ventral to the medial vestibular nucleus. It is fairly compactly arranged, except along its ventral aspect where some of its constituent cells are somewhat scattered in the reticular gray. The reconstruction (fig. 18) emphasizes the lateral turn of the nuclear column but does not show its ventral bend. The relation of the inferior salivatory to the superior salivatory nucleus is seen in this reconstruction. The rostrocaudal extent of the superior salivatory nucleus is $0.6 \mathrm{~mm}$.

The ventral facial nucleus in the adult rabbit. The ventral facial nucleus is located in the caudal regions of the pons near its ventro- 
lateral surface. It is ventromedial to the nucleus of the spinal root of the trigeminal nerve and lateral to the trapezoid gray. Dorsal to its rostral half is the accessory abducens nucleus. Caudally it is in close relation with the nucleus ambiguus, the cells of this latter gray column extending somewhat rostral to the caudal limit of the ventral facial nucleus. Rostrally it is closely associated with the superior olive. The nucleus is readily divided into a dorsal, a lateral, a medial, and an intermedioventral group (fig. 16). Papez ('27) further divided this last group of cells into an intermediate, a ventrolateral, and a ventromedial group in the eat. The cells of this nucleus are multipolar neurons which stain rather deeply in toluidin blue preparations. They are larger than the neurons of the general visceral efferent cell column but not quite so large as those of the hypoglossal nucleus. The nuclei of these nerve cells stain somewhat lighter than does the surrounding cytoplasm, which appears quite granular. In reconstruction the nuclear mass has an irregularly rectangular appearance with a rostrocaudal extent of $2.95 \mathrm{~mm}$., which is slightly greater than its mediolateral dimension (fig. 19).

\section{The trigeminal}

In the 11-day embryo. The trigeminal nerve has its central origin from the common efferent cell column (fig. 1a and see also p. 86). The cells giving rise to the motor root of the trigeminal nerve appear to be confined to a single neuromere, which is located at the pontine flexure (A of fig. 1a) and is the second rostral to that giving superficial origin to the facial nerve.

Neuraxes of the trigeminal efferent neurons course ventrolaterally through the brain stem and emerge from the surface as several small fascicles, ventromedial to the caudally directed processes of the sensory root. Just before their emergence the more rostral fascicles are joined by a small contribution from the primitive nucleus of the mesencephalic root (fig. 12). From their superficial origin the rootlets turn slightly caudad (and at the same time ventrolateralward) to gather into a fairly compact root which passes among the loosely arranged cells of the posterior portion of the semilunar ganglion and, just ventrolateral to it, is joined by the dendrites of cells located in this part of the ganglion, thus composing the mandibular ramus of the trigeminal nerve. This ramus continues ventrolaterally and slightly caudalward into the mandibular portion of the first branchial arch, within which it is distributed (fig. 2). The only signs of branching are fine filaments indiscriminately seattered along its path. The maxillary ramus, which is entirely sensory and originates from intermediate cells of the semilunar ganglion, is loosely distributed within 
the maxillary portion of the first branchial arch. The ophthalmic ramus, also entirely sensory and arising from the rostralmost cells of the ganglion, is represented by a very few fine fibers rostrolateral to the ganglion (fig. 2).

In the 12-day embryo. Other than an increase in the number and the size of its neurons the common efferent cell column shows very little differentiation beyond that of the 11-day embryo. The efferent root of the trigeminal is now definitely composed of neuraxes of cells located within two neuromeres: the segment which gives superficial origin to the nerve ( $A$ of fig. 1a) and that just caudal ( $B$ of fig. 1a). The neuraxes of the caudally located neurons course ventrolateral to the lateral surface of the efferent cell column and, collecting into a single bundle, turn rostrally within the brain stem to the level of emergence of fascicles from neurons of the more rostral neuromere. Then they turn ventrolateralward to combine with the remainder of the nerve as it emerges from the brain stem.

Peripherally the three rami show an increased development (fig. 3 ). The mandibular portion reaches farther toward the periphery and indications of branching are evident. The maxillary division, still quite loosely scattered in the developing upper jaw region, extends nearer the lip area. The ophthalmic ramus is decidedly more prominent, but, instead of a single trunk, it is distributed from the rostral end of the ganglion as three separate nerves. The most dorsal of these is the combined frontal and nasal branch, which divides into these respective parts in its peripheral termination in the temporal area. The other two branches are ciliary branches which leave the ganglion ventrocaudal to the fronto-nasal branch and are distributed independently toward the eye region (fig. 3 ).

In the 13-day, 2-hour embryo. The central nuclear masses of the trigeminal nerve (figs. 21 and $22 \mathrm{a}$ ) are beginning to differentiate and the common visceral efferent cell column has appeared and is continuous throughout the rostrocaudal extent of the brain stem, the portion giving rise to the motor trigeminal root being continuous caudally with the cells of origin of the facial nerve (fig. 22a) and rostrally with a similarly located, but not so well differentiated, column in the mesencephalon. The dorsalmost portion of this column in the mesencephalon is giving rise to the neurons of the primitive mesencephalic nucleus of the trigeminal nerve. At the level of the emergent trigeminal nerve the columnar arrangement is not so definite as in the more caudal region since the cells follow the contour of the brain segments (fig. 1a), which are still prominent. Laterally the column is bordered by the developing chief sensory nucleus, and internuclear connections between the two cell groups are prominent (fig. 17). The efferent and 
afferent columns are not distinctly separated but they can readily be distinguished by their differences in staining and in cellular eharacteristics (fig. 21). The neuraxes of the efferent cells pass toward the periphery of the brain stem directly among the medioventral neurons of the primitive chief sensory nucleus. The contribution from the mesencephalic nucleus to the emergent trigeminal root is larger than in the earlier stages and some of the mesencephalic root fibers appear to continue caudally in the brain stem.

The peripheral branches show a decided development over those of the 12-day embryo (figs. 4 and 12). The two divisions of the mandibular ramus are distinguishable. The anterior division shows some branching in the region of the pterygoid muscles, and definite lingual, mylohyoid, and inferior alveolar branches arise from the posterior division (fig. 4). The lingual branch is joined by the chorda tympani nerve as it is distributed ventromedially toward the tongue (fig. 4). The maxillary ramus is still quite scattered as it passes ventrolaterally to the developing eye. The superior alveolar and palatal branches are present as undifferentiated bundles ventromedial to the main trunk of the nerve and the more medial filaments (the primitive sphenopalatal branches) are in close relationship with the terminal twigs of the greater superficial petrosal nerve from the facial (fig. 4). The ophthalmic ramus is still uncollected as it leaves the semilunar ganglion, the frontal, nasal, and ciliary branches arising independently (fig. 4).

In the 14-day, 6-hour embryo. The nuclear grouping is more definite than previously. The efferent cells, some of which are multipolar, are gathering in the ventrolateral area of the pons medial to the fairly well differentiated chief sensory nucleus (fig. 25). Scattered neurons are still found in the region dorsomedial to the developing motor nucleus and as far caudad as the emergent facial root (fig. 27).

Neuraxes from the trigeminal efferent neurons are distributed in three directions. In the first place, the major portion converges toward the lateral aspect of the trigeminal motor nucleus, there turning caudad between the motor and sensory nuclei to emerge from the ventrolateral surface of the brain stem medioventral to the sensory root (fig. 25) ; secondly, neuraxes from the scattered, medially located cells cross the midline and emerge as the lateralmost fibers of the contralateral efferent root; and, lastly, a very fine group from the more dorsally located of the scattered medial neurons courses toward the midline for a short distance and then turns caudad (figs. 25 and 27) toward the emergent facial root. This last group is lost in sections just rostral to the emergent facial root (see p. 140). The crossing root fibers are accompanied by processes from the cells of 
the chief sensory nucleus, some of which end about the more medially located, contralateral efferent neurons (fig. 27), and others of which enter the homolateral and contralateral dorsal secondary ascending tracts of this nerve.

Peripherally (figs. 11-14, 25 and 26), the rami of the trigeminal nerve show considerable development over those of the 13-day, 2-hour embryo. The mandibular ramus is clearly divided into its anterior and posterior divisions and all but the tensor tympani and tensor veli palatini branches are discernible. Ventromedially directed branches from the maxillary ramus are still profusely intermingled, and superior alveolar and spheno-palatine branches are not distinguishable as such. However, the medial branches are associated with the greater superficial petrosal nerve. A few sympathetic ganglion cells scattered among them indicate the beginning of the sphenopalatine ganglion. The zygomatic branch, arising from the maxillary ramus near its origin from the semilunar ganglion, is distributed dorsolaterally toward the developing eye. The terminal portion of the maxillary ramus, the infraorbital nerve, ends superficially by dividing into three distinct parts, thus indicating the superior labial, the nasal, and the inferior palpebral branches. The ophthalamic ramus still originates from the semilunar ganglion in several independent branches. The frontal branch is closely related to the trochlear nerve as the former courses toward its area of termination, dorsal and rostrodorsal to the developing eye. The nasal branch extends anterolaterally toward the periphery and an anastomotic branch is found between it and the frontal nerve just rostrodorsal to the optic nerve. The two ciliary branches still leave the ganglion independently; the more dorsal, coursing forward dorsal to the optic nerve and bending ventrally just as it terminates, points toward the primitive ciliary ganglion; the other runs directly forward toward this area from its origin. The lachrymal branch is indicated by a few fibers arising from the ganglion between the origin of the ciliary nerves and the maxillary ramus.

In the 14-day, 21-hour embryo. The trigeminal motor nucleus is fairly well formed in the ventrolateral area of the pons. A few cells are scattered medial to the nucleus but the majority have either migrated into the main group, as in the rostral levels of this nucleus, or into its primitive caudal limb (fig. 28). This nuclear complex is characterized by embryonic neuroglia and more of its neurons are multipolar than in the 14-day, 6-hour embryo. Neuraxes from the medially located cells within the rostral portion of the column arch dorsally and laterally (fig. 25) over the nucleus to gain its lateral aspect. Here they turn ventrolaterally toward the surface of the brain stem and emerge with neuraxes of the laterally placed cells. Neuraxes 
from the cells of the caudal limb of this nucleus course dorsally and tend to converge into a single fascicle, which swings dorsolaterally across the superior aspect of the emergent facial root (Woodburne, '36) and enters the emergent root as its most caudal component.

The trigeminal nucleus extends caudally to the cephalic tip of the ventral facial nucleus. Only the rostralmost cells of this gray column connecting the trigeminal and facial nuclei definitely contribute to the trigeminal motor root. The remainder of the column ultimately forms the accessory abducens nucleus and further experimental investigation is necessary to determine the distribution of this accessory abducens group (see pp. 101 and 135).

The branch of the trigeminal nerve to the tensor tympani muscle arises from the nerve to the internal pterygoid muscle. The lachrymal branch is more highly developed than previously and receives about equal contributions from the maxillary and ophthalmic rami. The ophthalmic ramus is more compact than in the previous stage and sympathetic ganglion cells are present about the terminations of the ciliary branches. The superior alveolar branches are distinguishable and the palatal branches have increased relations with the terminal filaments of the greater superficial petrosal and the deep petrosal nerves (these two latter branches entering this region as independent structures). The number of cells has increased in the developing sphenopalatine ganglion and the terminal branches of the trigeminal and facial nerves have a few anastomoses in the region of the mandible.

In the 15-day, 6-hour embryo. A few cells are still found medial to the efferent nucleus which contribute, for the most part, to the contralateral root. Some of the more adjacent cells send their processes into the homolateral root along with those of the dorsomedial portion of the main nuclear mass.

The terminal trigeminal branches extend farther toward the periphery and the bundle to the tensor veli palatini is distinguishable. There are more anastomoses between the terminal branches of this nerve and those of the facial in the lower regions of the face and about the mouth than in the previous stage.

In the 16-day, 6-hour embryo. All of the cells have not completely migrated into the main nucleus. The caudal limb of the nucleus apparently has shifted ventrolaterally in its rostral portion and is now directly continuous with the main group of cells along its ventromedial aspect. Caudally this group of cells (including the undifferentiated accessory abducens nucleus) extends, uninterruptedly, to the level of the facial nucleus and overlies the more rostral cells of this structure. 
Peripherally, the zygomatico-faeial branch shows further anastomoses with the terminal branches of the facial nerve. The sphenopalatine ganglion has greatly increased in cell content and the invading fibers from the greater superficial petrosal and deep petrosal nerves enter it as a common trunk, the vidian nerve, to anastomose with the terminal filaments of the palatal branches of the trigeminal nerve.

In the 17-day embryo. All of the cells contributing to the motor root of the trigeminal nerve have gathered into its efferent nuclear complex and they all appear to be multipolar. Except for general development and further distribution within the areas previously invaded the nerve shows no further differentiation peripherally.

In the 20-day embryo. The motor nucleus is more compactly arranged than at earlier stages. A constriction in the gray column which in earlier stages connected the facial and trigeminal nuclei indicates the beginning of differentiation of the boundary between the motor trigeminal nucleus and the accessory abducens nucleus (fig. 29a). Peripherally the lachrymal and the zygomatico-temporal branches show anastomoses with the temporal portion of the facial nerve. These anastomoses are due not only to the increased distribution of these branches but primarily to the invasion of the facial nerve into the region.

In the 25-day embryo. The only apparent change at this age is an increase in size of the neurons of the motor nucleus. These cells do not have adult characteristics but show more processes and a more uniform distribution of neurofibrils than in any previous stage.

In the 1-day-old rabbit. The neuroglia of the efferent nucleus of the trigeminal nerve has lost its embryonic characteristics and the nucleus appears encapsulated by fibrous elements (fig. 17). The neurons have an adult appearance due to an increase in their size and in the number of their processes.

In the 6-day-old rabbit. No further changes are found in the central complex of the trigeminal nerve. Peripherally, the terminal branches show a greater development and, in the temporal regions, there are increased relations with the terminal branches of the facial nerve, otherwise there are no changes from the conditions described previously.

The trigeminal motor nucleus in the adult rabbit. This gray mass (figs. 14, 17 and 25) is medial to the chief sensory nucleus, ventromedial to the caudal limit of the nucleus of the mesencephalic root, directly dorsal to the superior olive, and ventrolateral to the fourth ventricle. It is the most rostral representative of the special visceral efferent column (fig. 19). The caudal limb of the nucleus extends 
caudally, from its medioventral aspect, and is in direct line with, although separated from, the accessory abducens nucleus.

The cells of the trigeminal motor nucleus are large, multipolar elements with marked chromophile staining and resemble those of the ventral facial nucleus. They show a large, lighter staining nucleus with one or two nucleoli.

In cross sections the nucleus has a somewhat folded appearance and can be divided into four rather indistinct cell groups-a lateral group composed of the greater number of cells, a medial group, which in its rostral region is subdivided into a ventral and a dorsal division; and the group of the caudal limb. The first three groups are more evident in the rostral levels of the nucleus. In reconstruction the nucleus is quite irregular (fig. 19) and shows a greater mediolateral diameter in its rostral one-half. Its length, exclusive of its caudal limb, is $2.6 \mathrm{~mm}$.

\section{GENERAL DISCUSSION}

In the preceding pages a detailed account of the differentiation of the bulbar efferent cranial nerve nuclei and of the development of their peripheral branches (including also those of the sensory roots) has been given. This discussion concerns itself only with the outstanding, general changes which occur during the differentiation of the efferent nuclear groups of the bulbar cranial nerves.

The brain stem gray of young embryos shows a definite segmentation and each of the neuromeres thus formed contributes fascicles to one or more cranial nerves. The trigeminal nerve originates from the first and second bulbar neuromeres, the facial from the third and fourth bulbar segments, the abducens from the fourth, the glossopharyngeal from the fifth, and both the vago-accessory and the hypoglossal nerves from the sixth, which is the most caudal of the bulbar segments.

The efferent roots of the cranial nerves have their origin from a common efferent cell column in the young embryos. This column is continuous throughout the brain stem and extends caudally into the spinal cord. It is located ventrolaterally, below the ventricle, and presents no differentiation (such as nuclear grouping) at the levels of origin of the various nerves. In its progressive development this common efferent cell column first differentiates into a somatic efferent and a 
common visceral efferent column, with the somatic efferent cells located medial to those which are visceral gray. Multipolarity of the neurons of these columns gradually appears during development and then some of the larger multipolar cells of the common visceral efferent column begin to migrate ventrolaterally from their primitive positions to form the special visceral efferent column.

Simultaneously with the differentiation of the special visceral efferent cell column the peripheral mesenchyme makes rapid progress in development into primordial muscle groups. Thus the peripheral development proceeds step by step with the differentiation of the central nervous system.

As the migration into the special visceral efferent gray column is nearly completed, indications of the separation of the columns into nuclear groups becomes evident, and thus are formed the hypoglossal and abducens nuclei of the somatic efferent column, the dorsal efferent, the inferior salivatory, and the superior salivatory nuclei of the general visceral efferent column, and the nucleus ambiguus, the facial motor nucleus, and the trigeminal motor nucleus of the special visceral efferent column are formed. A sub-grouping of the cells within the various nuclei rapidly follows the beginning of differentiation of the columns into nuclear groups.

The above study shows the great degree of interrelation between the nuclear and fiber differentiation of the medulla oblongata and the stage of development of the peripheral motor mechanisms. It also shows how beautifully the ontogenetic development in the nervous system, as in other parts of the body, repeats the phylogenetic history.

\section{LITERATURE CITED}

Addens, J. L. 1933 The motor nuclei and roots of the eranial and first spinal nerves of vertebrates. Zeitsehr. f. Anat. u. Entwicklungsgeschichte, I. Abteil. d. Zeitschr. f. ges. Anat., Bd. 101, S. 307-410.

1934 A critical review of the occurrence of crossing root-fibres in the facialis, vestibular, glossopharyngeal, and vagus nerves. Psyehiat. en Neurol. Bl., Jaarg. '34, pp. 274-291. 
Allen, W. F. 1919 Application of the Marcli method to the study of the radix mesencephalica trigemini in the guinea-pig. J. Comp. Neur, vol. 30, pp. $169-216$.

1923 Origin and distribution of the tractus solitarius in the guinea pig. J. Comp. Neur., vol. 35, pp. 171-204.

1927 Experimental-anatomical studies on the visceral bulbo-spinal pathway in the cat and guinea-pig. J. Comp. Neur., vol. 42, pp. 393-456.

Arey, L. B. 1931 Developmental Anatomy. W. B. Saunders Co., Philadelphia.

ARIËNs KapPkRs, C. U. 1910 Weitere Mitteilungen über Neurobiotaxis. V. The migrations of the motor cells of the bulbar trigeminus, abducens and facialis in the series of vertebrates, and the differences in the course of their root-fibers. Verhandl. d. kon. Akad. v. Wetensch. te Amsterdam, Tweede Sectie, Deel 16, no. 4, S. 1-195.

1911 Idem. VI. The migrations of the motor root-cells of the vagus group, and the phylogenetic differentiation of the hypoglossus nucleus from the spino-oceipital system. Psychiat. en Neurol, Bl., Amsterdam, vol. 15 , S. 408-427.

1912 Idem. VII. Die phylogenetische Entwicklung der motorischen Wurzelkerne in Oblongata und Mittelhirn. Folia neuro-biol, Bd. 6, Sommer-Ergänzungs-Heft, S. 1-142.

1913 Phenomena of neurobiotaxis in the central nervous system. Transactions of the XVII International Congress of Medicine, London, secs. 1 and 2, part 2, pp. 109-122.

1914 Der Geschmack, perifer und central. Zugleich eine Skizze der phylogenetischen Veränderungen in den sensibelen VII, IX und $\mathbf{X}$ Wurzeln. Psychiat. en Neurol. Bl., Arusterdam, Bd. 18, S. 82-138.

1920 Vergleichende Anatomie des Nervensystems. E. F. Bohn, Haarlem.

Ariëns Kappers, C. U., G. Carl Huber and E. C. Crosby 1936 The comparative anatomy of the nervous system of vertebrates, including man. The Macmillan Company, New York.

BARNARD, J. W. 1936 A phylogenetic study of the visceral afferent areas associated with the facial, glossopharyngeal, and vagus nerves, and their fiber connections. The efferent facial nucleus. J. Comp. Neur., vol. 65, pp. 503-602.

BECCARI, N. 1913 Sulla spettanza delle fibre del Lenhossek al sistema del nervo accessorio e contributo alla morfologia di questo nervo. (Osservazioni in Lacerta muralis.) Arch. ital, di anat. e di embriol., vol. 11, pp. 299-351.

1922 Studi comparativi sulla struttura del Rombencefalo. I. Nervi spino-occipitali e nervo ipoglosso. II. Centri tegmentali. Arch. ital. di anat. e di embriol., vol. 19, pp. 122-291.

voN BEch'TEREW, W. 1899 Die Leitungsbahnen im Gehirn und Rückenmark. 2 ${ }^{\text {to }}$ A ufl., Leipzig.

BERKFLBACH VAN DFR SPRENKEL, H. 1924 The hypoglossal nerve in an embryo of Erinaceus Europaeus. J. Comp. Neur., vol. 36, pp. 219-270. 
BLACK, D, 1917 The motor nuclei of the cerebral nerves in phylogeny: A study of the phenomena of neurobiotaxis. Part I. Cyclostomi and Pises.

J. Comp. Neur., vol. 27, pp. 467-564.

Bochenek, A. 1901 La racine bulbo-spinale du trijumeau et ses connexions avee les trois branches peripheriques. Le Névraxe, vol. 3, pp. 107-119.

BoK, S. T. 1915 Die Entwicklung der Hirmerven und ihrer zentralen Bahnen. Die Stimulogene Fibrillation. Folia neuro-biol., Bd. 9, s. 475-565.

BREMER, J. L. 1908 Aberrant roots and branclies of the abducent and hypoglossal nerves. J. Comp. Neur., vol. 18, pp. 619-639.

1921 Recurrent branches of the abducens nerve in human embryos. Am. J. Anat., vol. 28, pp. 371-397.

OAstaldor, L. 1923 Studi sulla struttura e sullo sviluppo del mesencefalo. Ri cerche in Cavia cobaya. Areh. ital. di anat. e di embriol., vol. 20, pp. $23-226$.

Désḱrine, J. 1895 Anatomie des centres nerveux. Rueff et Cie, Paris.

Dixon, A. F. 1896 On the development of the branches of the fifth cranial nerve in man. Sc. Tr. Roy. Dublin Soc., vol, 6, Ser. 2, pp. 19-76.

DuBois, F. S. 1929 The tractus solitarius and attendant nuclei in the Virginian opossum (Didelphis virginiana). J. Comp. Neur., vol. 47, pp. 189-224.

Edinger, L. 1908 Vorlesungen über den Bau der nervösen Centralorgane des Mensehen und der Thiere. ; $^{\text {te }}$ Aufl., F. C. Vogel, Leipzig.

FAHsy, N. 1927 A note on the intracranial and extracranial parts of the IXth, $X$ th, and XIth nerres. J. Anat., vol. 61, pp. 298-301.

Fuse, G. 1912 Ueber den Abduzenskern der Sauger. Arb. a. d. hirnanat. Inst. in Zurich, Bd. 6, S. 401-447.

van Gehuohten, A. 1897 Anatomie des systeme nerveux de l'homne. A. Uystpruyst-Dieudonné, Louvain.

1899 Sur l'existence ou la non-existence de fibres croiseés dans le trone des nerfs moteurs craniens. J. de neurol., vol. 4, pp. 7-10.

1903 Recherehes sur l'origine réele et le trajet intracérébral des nerfs moteurs par la méthode de la dégénérescence wallérienne indirecte. Le Névraxe, vol. 5, pp. 263-337.

Hinsey, J. C., AND K. B. Corbin 1934 Observations on the peripheral course of the sensory fibers in the first four cervical nerves of the eat. J. Comp. Neur., vol. 60, pp. 37-44.

Huber, G. CARL, AND S. R. GuILD 1913 Observations on the peripheral distribution of the nervus terminalis in mammalia. Anat. Rec., vol. 7, pp. 331353.

Hunt, J. R. 1908 The sensory system of the facial nerve and its symptomatology. J. Nerv. and Ment. Dis., vol. 36, pp. 321-350.

Husten, K, von 1924 Experimentelle Untersuehungen über die Beziehungen der Vaguskerne zu den Brust- und Bauchorganen. Zeitschr. f. d. ges. Neurol. u. Psychiat., Bd. 93, S. 763-773.

Johnston, J. B. 1909 The radix mesencephalica trigemini. J. Comp. Neur., rol. 19 , pp. $593-644$.

KAIDA, Y. 1929 Ueber den Ursprung und den peripheren Verlauf der sogenannten zentrifugalen Vestibularisnerven nach Leidler (Fasciculus vestibularis medialis nach Kaplan). Areh. f. Ohren-, Nasen- u. Kehlkopfh., Bd. 123, S. 62-69. 
KeIbel, F., AND F. P. Mall 1912 Human embryology. Vol. II. J. B. Lippineott Co., Philadelphia.

Kohnstamm, O. 1902 Zur anatomisehen Grundlegung der Kleinhirn-Physiologie. Arch. f. d. ges. Physiol., Bd. 89, S. 240-252.

voN Kölliker, A. 1896 Handbuch der Gewebglehre des Menschen, Teil 2, W. Engelmann, Leipzig, 1889-1902.

Koox, F. H. 1917 The inferior olive in vertebrates. Folia neuro-biol., Bd. 10, S. 205-369.

Kosaka, K. 1909 Ueber die Vaguskerne des Hundes. Neurol. Centralbl., Bd, 28, S. $406-410$.

Kosaka, K., and K. Yagita 1905 Experimentelle Untersuchungen über den Ursprung des N. vagus und die centralen Endigung der dem Plexus nodosus entstammenden sensibilen Vagusfasern, sowie über den Verlauf ihrer secundären Bahn. Shinkeigaku Zasshi, Tokyo, Bd. 4, S. 29-49. (Quoted from Allen, '27.)

MALONE, E. F. 1913 The nucleus cardiacus nervi ragi and the three distinet types of nerve cells which innervate the three different types of muscle. Am. J. Anat., vol. 15, pp. 121-129.

MESDAG, T. M. 1909 Bijdrage tot de ontwikkelingsgeschiedenis van de structuur der hersenen bih het kip-embryo. Dissert., Groningen.

Molhan'r, M. 1910 Le nerf vague. Étude anatomique et experimentale. Partie I. Le noyau dorsal du vague, ses connexions anatomiques et sa valeur fonctionelle. Le Nérraxe, vol. 11, pp. 131-244.

PAPEZ, J. W. 1927 Subdivisions of the facial nucleus. J. Comp. Neur., vol. 43, pp. 159-191.

Pearson, A. A. 1938 The spinal accessory nerve in human embryos. J. Comp. Neur., vol. 68, pp. 243-266.

1939 The hypoglossal nerve in human embryos. J. Comp. Neur., vol. 71, pp. 21-39.

Preziuso, L. 1924 Sul nucleo acessorio del nervo abducente in alcuni uceelli e mammiferi. Nuovo Ercolani.

RAmón y CAJAL, S. 1895 Apuntes para el estudie del bulbo raquideo, cerebello $y$ origen de los nervios encefalicos. XVI. Nucleo del facial. Madrid. Anales de Historia Natural, Sesion del 6 de Febrero de 1895.

1909-1911 Histologie du système nerveux de l'homme et des ver. tébrés. A. Maloine, Paris.

RoLuER, F. C. W. 1881 Ein kleinzelliger Hypoglossuskern, Arch. f. mikr. Anat, Bd. 19 , S. $383-395$.

SABIN, F. R. 1901 An atlas of the medulla and midbrain. Friedenwald, Baltimore.

SANDERS, E. B. 1929 A consideration of eertain bulbar, midbrain, and cerebellar centers and fiber tracts in birds. J. Comp. Neur., vol. 49, pp. 155-222.

Sheinen, J. J. 1932 Typing of the cells of the mesencephalic nucleus of the trigeminal nerve in the dog, based on Nissl granule arrangement. J. Comp. Neur., vol. 50, pp. 109-129.

STADERINI, R. 1894 Sopra un nucleo di cellule nervose intercalato fra $\mathrm{i}$ nucleo di origine del vago e del ipoglosso. Monitore Zool. ital., vol. 5, p. 178. 
StREETER, G. L. 1905 The development of the cranial and spinal nerves in the oceipital region of the human embryo. Am. J. Auat., vol. 4, pp. 83-116. 1908 The peripheral nervous system in the human embryo at the end of the first month. Am. J. Anat., vol, 8, pp. 285-301.

STREeTER, G. L. 1912 Chapter XIV, Keibel and Mall's Enıbryology. (See under Keibel and Mall, '12.)

StuUrman, F. J. 1916 Die Lokalisation der Zungenmuskeln im Nucleus hypollossi. Anat. Anz., Bd. 48, S. 593-610.

1916 a Der Hypoglossuskern der Ameisenfresser. Anat. Anz., Bd. 49 , S. $342-348$.

Tello, J. F. 1922 Die Enstehungen der motorischen und sensiblen Nervenendigungen. Zeitsehr. f. d. ges. Anat., Bd. 64, s. 348.

TERNI, T. 1922 Ricerche sul nervo abducente $e$ in special modo intorno al significato del suo nucleo accessorio d'origine. Folia neuro-biol.. Bd. 12, S. $277-327$.

van VALKenburg, C. T. 1910 Nucleus facialis dorsalis, nucleus trigemini posterior, nueleus trochlearis posterior. Kon. Akad. v. Wetensch. te Amsterdam, Proc. sect. se., rol. 13, pt. 1, pp. 143-148.

Vermaulen, H. A. 1918 Die Accessoriusfrage. Psychiat. en neur. Bl., Amsterdam, vol. 22, pp. $729-742$.

VInCEnZI, L. 1884 Nate histologique sur l'origine de reelle quelques nerfs cerebraux. Areh. ital. de biol., vol. 5, p. 109.

WAKELEY, C. P. G., AND F. H. EDGeworth 1933 A note on the afferent nervesupply of the facial museles. J. Anat., vol. 67, pp. 420-421.

Waltanberg, A. 1897 Das dorsale Gebeit der spinalen Trigeminuswurzel und seine Beziehungen zum solitären Bündel beim Menschen.

Wainstein, Z. 1921 Ueber die motorischen Vaguskerne. Dissertation, Petersburg. (Quoted from Ariëns Kappers, Huber and Crosby, '36). Deutsche Zeitsehr, f. Nervenheilk., Bd. 11, S. 391-405.

WEED, L. 1914 A reconstruction of the nuclear masses in the lower portion of the human brain stem. Publ. Carnegie Inst., Washington, No. 191, pp. 1-78.

Weigner, K. 1901 Beziehungen des Nervus accessorius zu den proximalen Spinalnerven. Anat. Hefte, Abt. 1, Arb. A. Anat. Inst., H. 56/57 (B. 17 H. $3 / 4)$, S. $549-587$.

Weinberg, E. 1928 The meseneephalie root of the fifth nerve. A comparative anatomical study. J. Comp. Neur., vol, 46, pp. 249-405.

WINDLE, W. F. 1931 The sensory components of the spinal accessory nerve. J. Comp. Neur., vol. 53, pp. 115-127.

1933 Neurofibrillar development in the central nervous system of cat embryos between 8 and $12 \mathrm{~mm}$. long. J. Comp. Neur., vol. 58, pp. 643-723.

Winkler, C., AND A. Potrer 1911 An anatomical guide to experimental researches on the rabbit's brain. W. Versluys, Amsterdam.

Woodburne, R. T. 1936 A phylogenetic consideration of the primary and seeondary centers and connections of the trigeminal complex in a series of vertebrates. J. Comp. Neur., vol. 65, pp. 403-501.

Y AatTA, K. 1910 Experimentelle Untersuchungen über den Ursprung des Nervus facialis. Anat. Anz., Bd. 37, S. 195-218. 